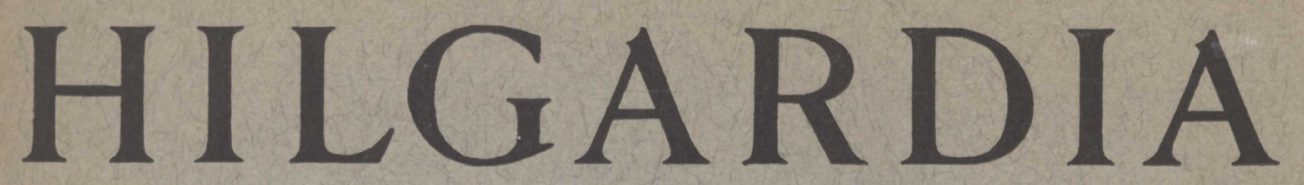

A Journal of Agricultural Science Published by the California Agricultural Experiment Station

\title{
MASS CULTURE OF CALIFORNIA RED SCALE AND ITS GOLDEN CHALCID PARASITES
}

\author{
STANLEY E. FLANDERS
}

UNIVERSITY OF CALIFORNIA - BERKELEY, CALIFORNIA 
THE golden chalcid, Aphytis chrysomphali (Mercet), has been parasitizing the California red scale, Aonidiella aurantii Mask., for more than fifty years in California citrus orchards. Planned use of this parasite, although seriously studied in 1942 and again in 1946, was not actually possible on a large scale until the completion of a culture method in the spring of $\mathbf{1 9 5 0}$ at the Riverside Insectary of the Division of Biological Control. This method made possible the production in commercial quantities of the California golden chalcid as well as a species, Aphytis sp. "A," brought from China in 1947.

During this study it was found that the Aphytis female has two addictions that may militate against its general use in the control of red scale. Under certain conditions this parasite temporarily immunizes its host to its attack, and it may destroy the pupae of its own species as well as those of other red scale parasites.

The use of inundative releases of the parasite for pest control depends largely on the populations released, not on their progeny. This type of control is similar to spraying and dusting in that a greater amount of lethal material is used than is actually effective, that repetition may be necessary, and that the effect is more or less immediate. 


\title{
H I L G A R D I A
}

A Journal of Agricultural Science Published by

the California Agricultural Experiment Station

\begin{tabular}{lll}
\hline VoL. 21 & MAY, 1951 & NUMBER 1 \\
\hline
\end{tabular}

\section{MASS CULTURE OF CALIFORNIA RED SCALE AND ITS GOLDEN CHALCID PARASITES ${ }^{1,2}$}

\author{
STANLEY E. FLANDERS ${ }^{3}$
}

\section{INTRODUCTION}

The possibility of controlling the California red scale, Aonidiella aurantii Mask., by the periodic inundative release of its natural enemies was first given serious consideration in 1942. In that year work began on the development of methods of propagating the golden chalcid, Aphytis chrysomphali (Mercet), in large numbers. Prior to that time the program of the University of California, Division of Biological Control, was based largely on the introduction and distribution of foreign entomophagous insects. War conditions, however, completely disrupted this program and at the same time drastically curtailed the production and distribution of insecticides. Also, by then it had become evident that the red-scale-feeding race of Comperiella bifasciata How., that had been introduced into California in 1940-41 from China, lacked the capacity to control effectively red scale on citrus (Flanders, 1944). As pointed out by Smith (1946) :

"... the periodic colonization of beneficial insects becomes desirable when the pest is not controlled by introduced parasites unaided. Generally speaking, most of the failure of introduced species to control their hosts comes about through faulty synchronization of host and parasite populations....

"Host distribution in time is at least as significant as host distribution in space from the standpoint of biological control, but its importance in this connection is often overlooked.... It is plain that the peak of the searching population must coincide in time with the occurrence of the susceptible host stages. Therefore the efficiency of a species as a control factor depends upon the synchronization of host and enemy population... The parasite Aphytis chrysomphali breeds freely only on certain stages of the red scale. There are periods when these stages are at a minimum. This reduces the parasite population to the point where it cannot overtake the host.... It would appear to be a sound program therefore to attempt to remedy this defect by the mass colonization of the beneficial species at the proper time in relation to the host population." The seriousness of red scale as a pest of citrus was being

\footnotetext{
${ }^{1}$ Received for publication December 6, 1950.

2 Paper No. 663, University of California Experiment Station, Riverside, California.

${ }^{3}$ Entomologist in the Experiment Station.

"See "Literature Cited" for citations, referred to in the text by author and date.
} 
accentuated in many localities during the period $1941-48$ by the clean-up of black scale, which resulted from the work of the introduced African parasite, Metaphycus helvolus (Smith, 1946), and of yellow scale by the action of the Japanese race of Comperiella bifasciata (Flanders, 1948).

In southern California the red scale in untreated orchards has been under attack by the California golden chalcid for more than fifty years. Natural control of red scale was observed occasionally. Woglum et al. (1947) reported that the California golden chalcid not infrequently accomplished very good commercial control. During 1920-23 in a natural control test plot in a lemon orchard on the Hewes Ranch at Tustin, California, the red scale was reduced to a very low ebb (H. M. Armitage, unpublished notes). Part of the mortality was obviously caused by this golden chalcid and part was at that time unexplainable.

In November, 1947, another golden chalcid was introduced into California from China (Smith and Flanders, 1949). Noting that the pupae of this chalcid differed from the California golden chalcid in having a black stripe lengthwise of the body, the writer designated it Aphytis sp. "A." The methods described herein were designed primarily for the culture of Aphytis chrysomphali. They are equally applicable, however, to the culture of the Chinese golden chalcid. It is quite possible that the latter can be propagated readily, using less expensive housing and equipment than is needed with the California golden chalcid since it reproduces under a wider range of environmental conditions. This advantage, however, is somewhat offset by the fact that about half the progeny of Aphytis sp. "A" consists of males. The term golden chalcid as used hereafter in this paper refers to either one or both species.

When the Chairman of the Division of Biological Control, Professor Harry S. Smith, in the spring of 1942 assigned to the writer the problem of developing methods for the mass culture of California red scale and its parasites, the necessity for the production of the parasites in very large numbers at very low cost was emphasized.

\section{EARLY INVESTIGATIONS}

In the summer of 1942 a culture of the California golden chalcid was established in the Division of Biological Control Riverside Insectary (fig. 1) employing the equipment and techniques developed for the culture of Comperiella (Flanders, 1943). This work, however, was side-tracked in the spring of 1943 when the writer was assigned the responsibility of developing a method for mass-producing the braconid Macrocentrus ancylivorus, parasitic on the Oriental fruit moth, Grapholitha molesta (Busck) (Finney, Flanders, and Smith, 1947). In the fall of 1944 the mass culture of Macrocentrus for field release was transferred to the Division of Biological Control Insectary at Albany, California, and experimentation on the mass culture of the California golden chalcid at Riverside was renewed.

The mature fruits of squash (Cucurbita) and melons (Citrullus) were infested with red scale by carefully brushing newly hatched red scale from mother infestations growing on grapefruit. When the infestation on the squash and melons had developed until the fruit was nearly covered with 
scale they were placed in the parasite rearing room where they remained, bearing generation after generation of host and parasite until the fruits deteriorated and were discarded.

Although this method had been quite satisfactory for producing Comperiella for establishment liberations, it fell far short of economically producing enough of the California golden chalcid for periodic mass release. The parasitization of the scale by the parasite was erratic. The spatial requirements for housing the infestations, the labor involved in handling the material, and the wastage of scale were excessive for the number of parasites obtained.

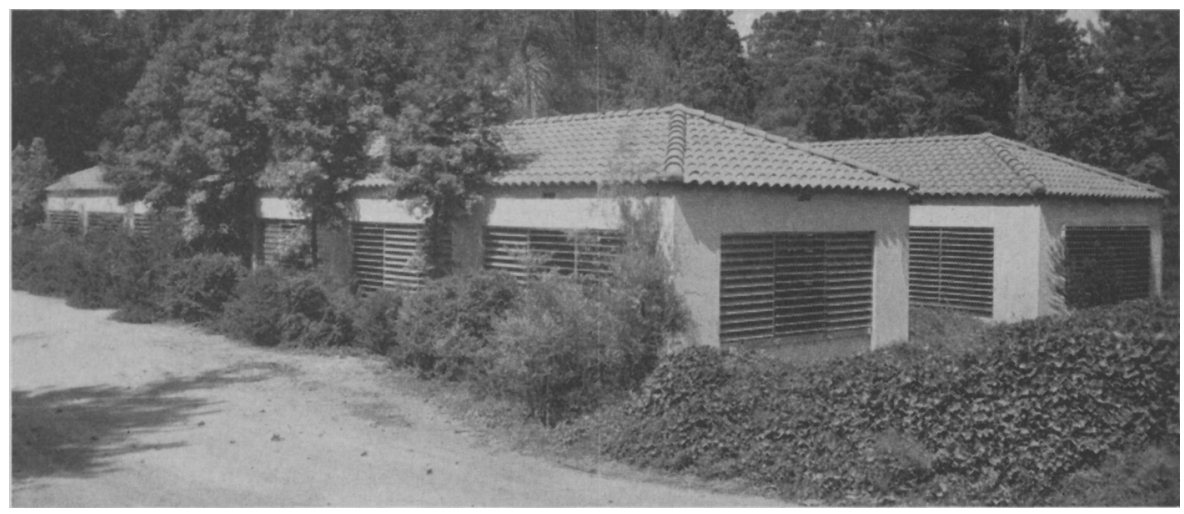

Fig 1. University of California Division of Biological Control Insectary at Riverside, California, with 20 air-conditioned rooms. Note that each window is equipped with aluminum Venetian blinds in three sections that are manipulated separately.

In the summer of 1945 a search began for a scale-supporting medium that would permit economical production of the parasite. Potted plants of citrus, willow, fig, and rose had been tested previously and found wanting (Smith, 1922). The principal difficulty was the lack of a method for adequately infesting the plants with scale (H. M. Armitage, February, 1923, report to H. S. Smith). It was obvious that, aside from being readily available, a satisfactory host plant should be of such a form and habit as to permit ease in handling and furnishing a large amount of infesting surface in a small amount of space. Date seedlings and iris planted closely in shallow trays fulfilled this requirement, but were inadequate from the standpoints of holding up under heavy infestations, of being cheaply and uniformly infested, and of obtaining maximum parasitization of scale.

In the summer of 1946 it was found that the red scale developed and reproduced in a normal manner on smooth-skinned White Rose potato tubers. By the end of the year a cheap yet efficient method was developed for producing and handling large quantities of red scale on mature egg-sized tubers (Flanders, 1947).

During 1946 and 1947 the production of red scale was used largely for the propagation of various coccinellids then being introduced into California from Africa (Smith and Flanders, 1949). During this period, small test 

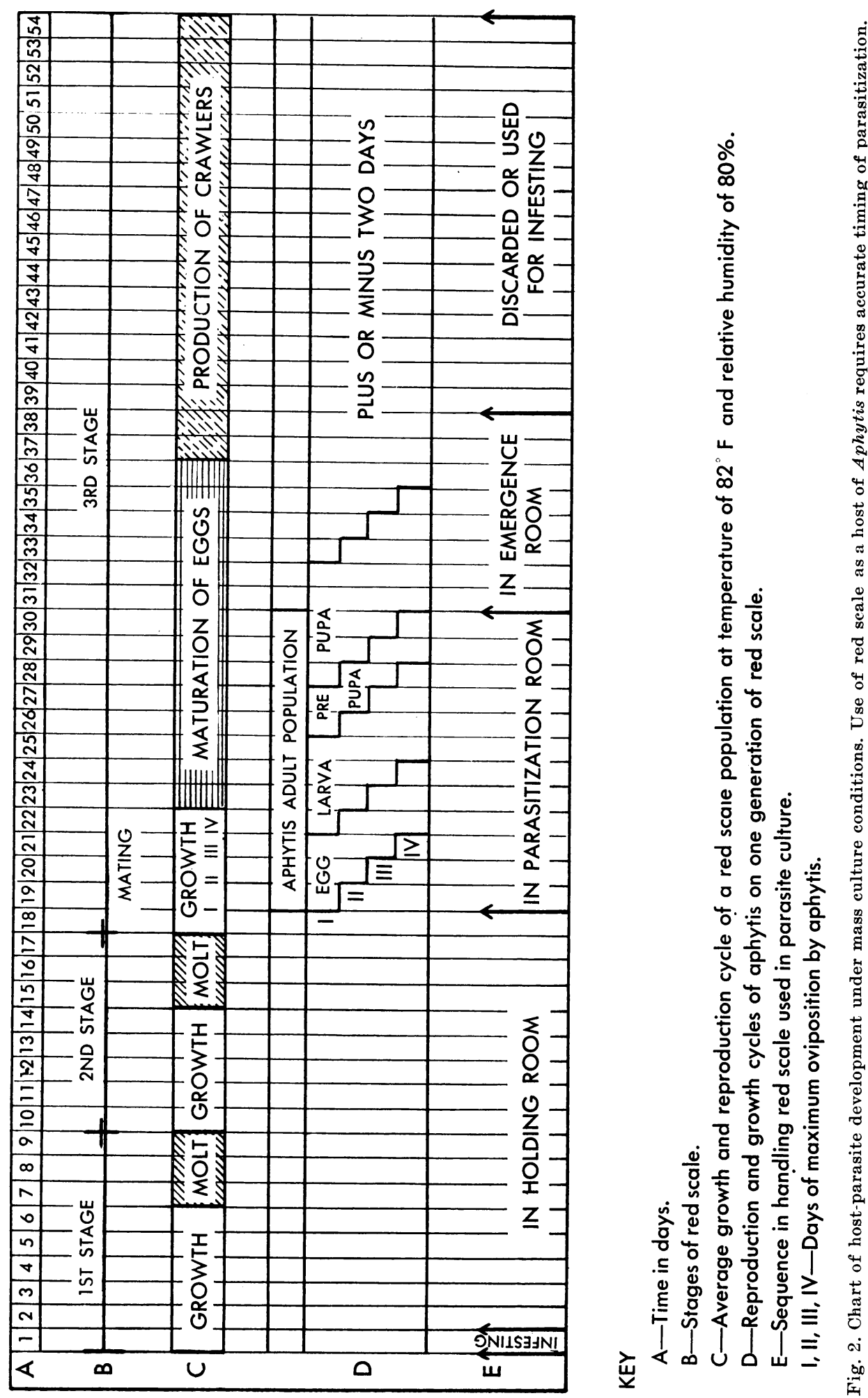
cultures of the California golden chalcid were under observation by C. E. Kennett, principal laboratory technician.

In the spring of 1948, investigational work on the mass culture of the California golden chalcid received renewed impetus as a result of field studies (DeBach, Fleschner, and Dietrick, 1948), which indicated that in certain citrus orchards in coastal districts the California golden chalcid unaided was satisfactorily controlling the red scale. Studies on the biology of the parasite were undertaken (Bartlett and Fisher, 1950) in an attempt to determine the cause of its erratic parasitization of its host. By the spring of 1950, however, a culture method was developed which made possible the production of the California golden chalcid as well as the Chinese species in commercial quantities.

\section{OUTLINE OF THE PROCESS OF GOLDEN CHALCID CULTURE}

The sequence of events from the birth of the red scale to the collection of its parasite is completed in a minimum period of 33 days at a temperature of about $82^{\circ} \mathrm{F}$ and humidity between 60 and 80 per cent. The red scale is exposed to parasitization when in its final parasite-supporting condition-a condition which (fig. 2) occurs during the growth period of the third instar. The developmental period of the parasite feeding on red scale is generally from 13 to 15 days.

Mature, egg-sized, smooth-skinned potato tubers packed in a layer on trays of hardware cloth are uniformly infested with newly hatched red scale blown by means of an air brush from mother infestations. The scale is held until the female scale attains a suitable host condition, and is then exposed to parasitization in a room containing a constant population of parasites sufficient in number to parasitize most of the scale within a period of 48 hours. On the twelfth day after being placed in the parasitization room the scale is transferred to another room where emergence of the adult parasites occurs.

The newly emerged golden chalcids are collected by means of an aspirator into transparent plastic tubes for shipment to the field. Collection is facilitated by having the parasites congregate on limited surfaces through tropic manipulation of the direction of movement, the newly emerged adults being positively phototropic and negatively geotropic.

\section{BIOLOGY OF THE RED SCALE}

The California red scale develops continuously generation after generation at temperatures between $60^{\circ}$ and $90^{\circ} \mathrm{F}$. Its primary host appears to be citrus, but it feeds on many other plants. Bisexual reproduction is obligatory with the sexes, occurring in equal proportions. Like other diaspine eoceids the female is sessile after it begins feeding on plant tissues. The red scale is ovoviviparous, the young nymphs remaining under the parental scale cover for a few hours and then emerging to search for a suitable feeding position. As stated by Quayle (1938):

"Upon settling, the young"scale draws its legs and antennae beneath the body and in an hour or two cottony secretion appears over the body. In 
another hour, light, cottony threads envelop the entire insect and extend down over its sides to the surface where it is becoming fixed. Once the red scale settles it remains fixed in position through its life, except that the winged male finally emerges from beneath its covering. The insect becomes circular and revolves about for the purpose of properly molding the covering. After a couple of days the covering, especially around the margin, becomes

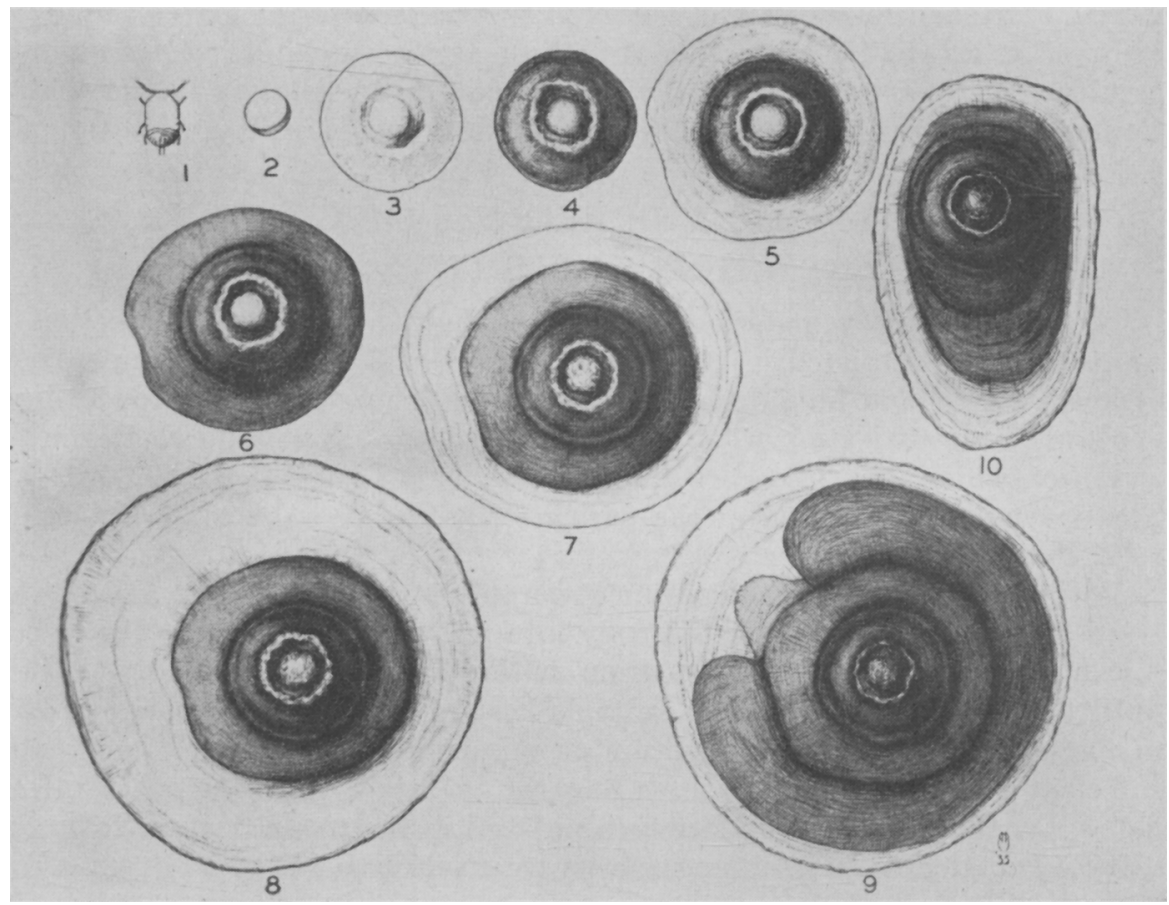

Fig. 3a. Developmental stages of California red scale exclusive of the adult male. (1) crawler; (2) white cap; (3) nipple stage; (4) first molt; (5) second stage with gray margin; (6) second molt with gray margin obliterated by growth of scale body underneath; (7) third stage with incomplete gray margin; (8) third stage with complete gray margin (mating stage); (9) third-stage gravid female; (10) scale covering under which the male transforms into prepupa, pupa, and adult (after Quayle).

more compacted. The form at this time is that of a cap with a flat top and vertical sides; hence the common designation at this period of 'white cap' (fig. 3a). After a few days this cap settles down around a center, leaving a small prominence or nipple;... As the covering increases in size it spreads out to a thin edge at the margin. In a week or two [a few days at $84^{\circ} \mathrm{F}$ ] all of the cottony effect is lost and the covering becomes a compacted film. After 12 or 15 days [ 10 or 12 days at $84^{\circ} \mathrm{F}$ ] the first exuvia or cast skin becomes incorporated into ... the covering. With the increased size of the insect after the first molt, it is necessary that the covering be enlarged, and so this is extended farther and farther beyond the cast skin when the second exuvia is incorporated into the covering and is about twice the size of the first 
exuvia, both forming concentric circles. The second molt occurs 10 or 12 days after the first...

"Preliminary to molting, the insect, which up to this time is readily separated from its covering, now becomes firmly attached to it. During this period the body wall is brittle instead of flexible as between molts, and is more distended and the body contents are much more fluid. The skin splits around the lateral margin, including the margin of the lobes and plates of the py-

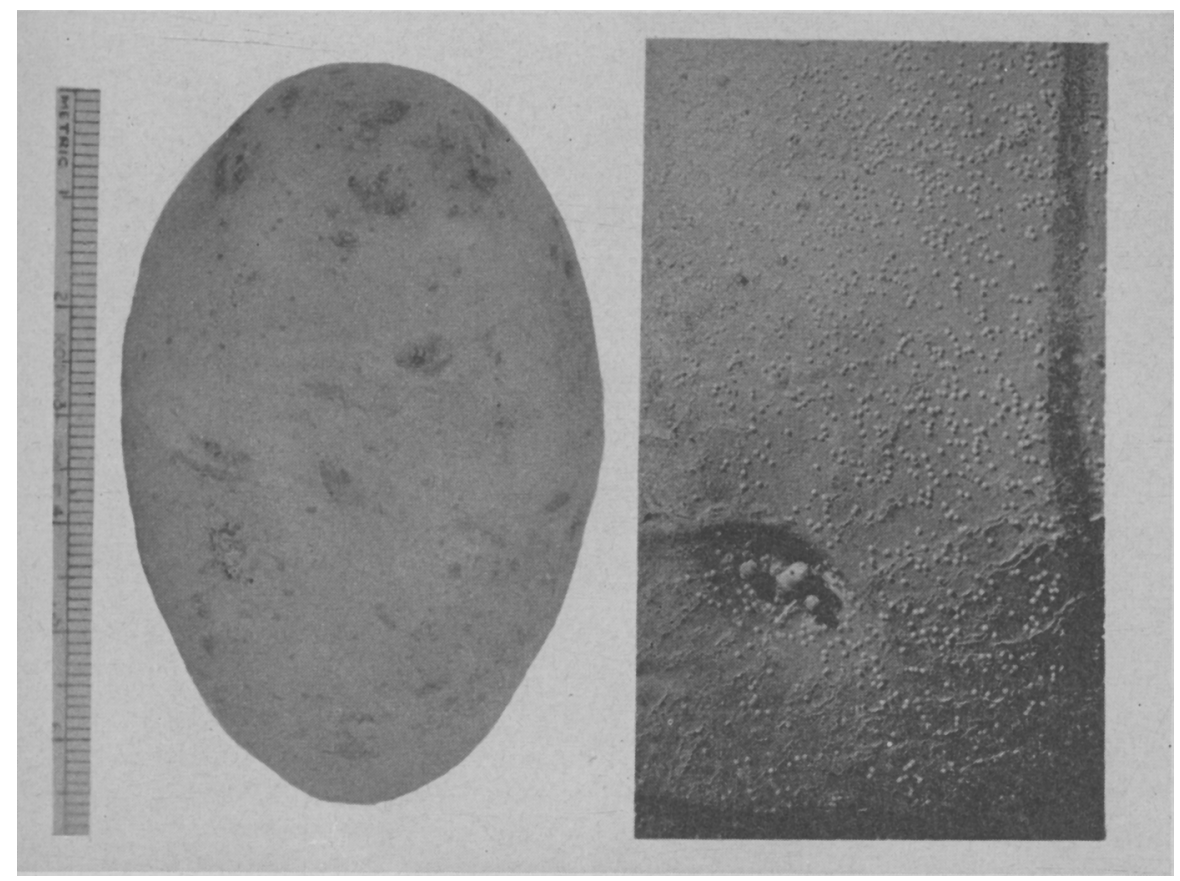

Fig. 3b. An infestation of red scale in "white-cap" stage on potato tuber. (Left) Whole tuber 24 hours after infesting. (Right) Enlarged section of tuber surface near "eye" showing an initial scale population of optimùm density. Less than 50 per cent of these scales will become third-stage females suitable for the development of Aphytis.

gidium ; consequently, the pygidial characters will be seen in the dorsal as well as the frail and almost invisible ventral part of the cast skin. In the first exuvia the legs and antennae may be seen because these are lost in the first molt. The time spent in the actual molting process lasts from 2 to 3 days...

"Upon completion of the second molt the insect again extends its covering until there is a wide gray margin of the covering extending beyond the insect body. This stage or period in the development of the insect is known as the gray adult (fig. 3a). It is during this period that fertilization occurs and soon thereafter the insect enters the young-producing period when the insect and its covering again become intimately associated and cannot be readily separated from one another. The longevity of the insect depends to a considerable degree on how long after maturity fertilization occurs. The insect may live in the gray adult stage at least six months if fertilization does not occur. 

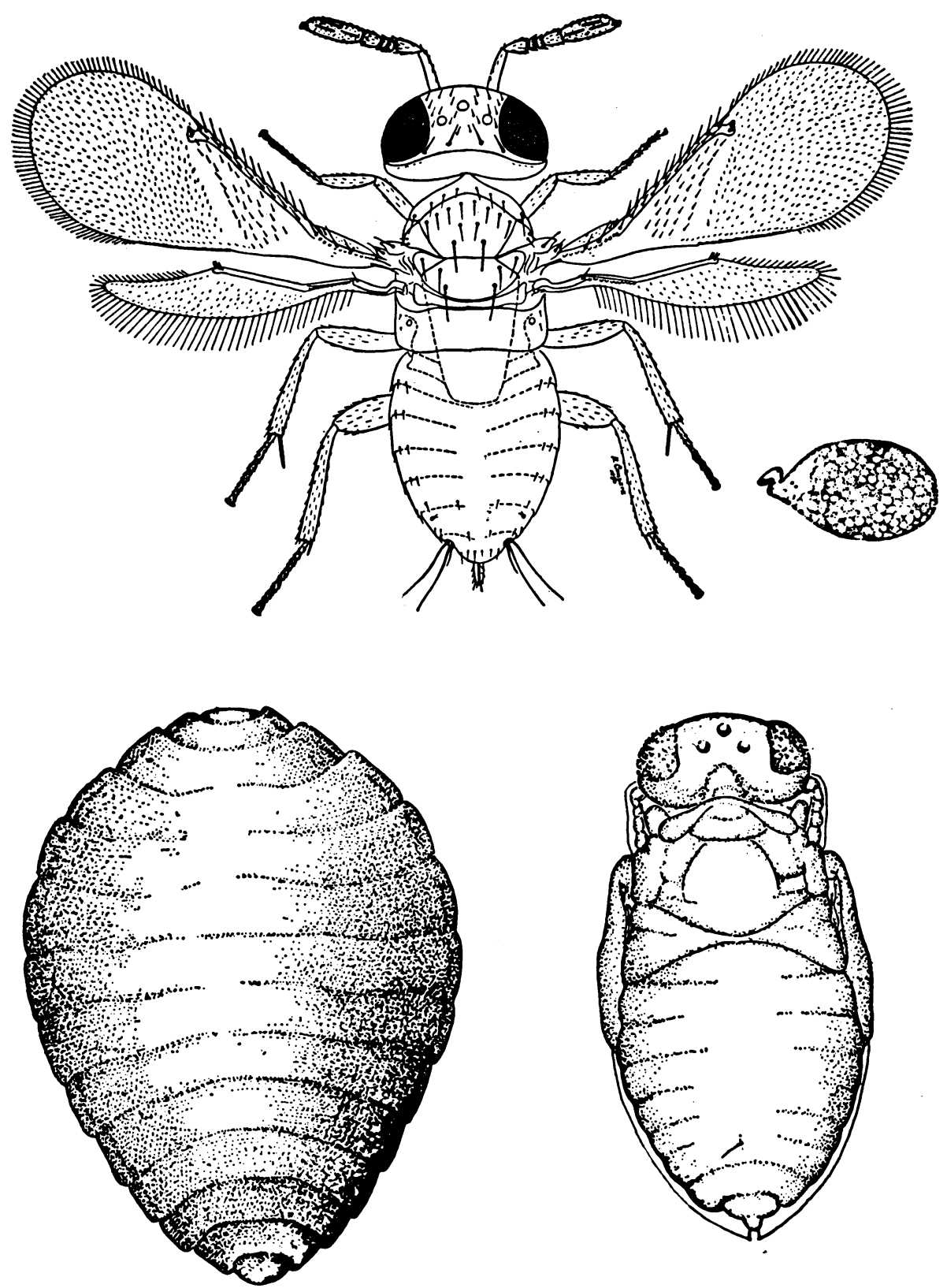

Fig. 4. Diagrammatic illustrations of adult Aphytis chrysomphali (Mercet) and its egg, larva, and pupa (after Quayle). In life this adult parasite is approximately $1 \mathrm{~mm}$ in length and pale yellow with green compound eyes. 
"After reaching maturity and being fertilized, young are brought forth at an average rate of two or three a day until about 150 are produced. The usual young-producing period lasts about two months ...

"The sexes are indistinguishable until after the first molt, when the scale of the male becomes elongate (fig. 3a). The pygidial characters are the same as in the second instar female but two pairs of conspicuous purple eyes appear. These eyes are not visible immediately after the molt, but develop during the period of the second instar. After the second molt the male enters the prepupal stage. The sheaths of the antennae and wings are visible and there is a slight indication of those of the legs. After the third molt the male enters the pupal stage. The style appears and the sheaths of the appendages are conspicuous. The fourth and last molt brings the male to the adult stage. The male pushes its way backward from beneath the scale covering that was completed during the time it was in the second instar. The male is orangeyellow and has a wing expanse of $1.5 \mathrm{~mm}$. It is of the usual male occid type, that is, it is a frail weak-flying insect with but one pair of wings, the second pair being replaced by a pair of hooked halteres, and with a long style."

At temperatures of $80^{\circ}$ to $84^{\circ} \mathrm{F}$ and humidities between 60 and 80 per cent the minimum life cycle is about 36 days, the first stage being about 9 days, the second stage about 8 days, and the third stage prior to a gravid condition about 19 days (Flanders, 1943).

A variable proportion of a population of red scale when developing on potato tubers lacks the capacity to form normal scale covers, the wax filaments forming a contorted white pile. The frequency of this wax malformation appears to be correlated with the aging of the tuber.

\section{BIOLOGY OF THE GOLDEN CHALCID}

The Callfornia Species. The golden chalcid, Aphytis chrysomphali (Mercet) (fig. 4), under California conditions is usually a unisexual species. It is known to develop only on Aonidiella spp. and Aspidiotus destructor Sign. The general coloration of the adult is uniformly pale lemon yellow, with its average length nearly $1 \mathrm{~mm}(0.75 \mathrm{~mm} \pm 0.25$ according to Bartlett and Fisher, 1950). Its length of life as an adult is about 10 days. (The mortality of a population is 50 per cent at the end of 8 to 9 days.) During this period it is capable of laying 6 or 7 eggs per day. When over a day old and in the presence of its host it tends to run rather than to fly. The preoviposition period is less than 24 hours.

The golden chalcid develops ectoparasitically, extracting the host's contents through openings cut in the body wall. The stages of development are described by Quayle (1911) as follows:

"The egg (fig. 4) is yellowish white in color, ovate in form, measuring $.16 \mathrm{~mm}$ long and $.96 \mathrm{~mm}$ wide. There is a conspicuous micropyle projecting from the narrower end and also attached to this a short stalk that is doubled back on itself. The chorion is smooth, with spherical granular bodies showing through with transmitted light.

"The larva when full grown appears as a more or less structureless topshaped globule, measuring, when segments are normally extended, $.75 \mathrm{~mm}$ long and $.5 \mathrm{~mm}$ wide. It tapers considerably more toward the posterior end, 
and there is a slight difference between the dorsal and ventral surfaces. The distance between the upper and lower surfaces is a little less than the width of the body so that there is sorne indication of flatness. The color is glassy white, with the food in the digestive tract showing distinctly yellow, oval in shape, and measuring about one half the dimensions of the larva itself. There are thirteen indistinct segments, not including the button at the tip. The head end is broadly rounded, with the first segment disc-shaped and firmer than the others, with the small mouth opening in the center. This mouth opening is about $.20 \mathrm{~mm}$ in diameter, and there are two chitinous spines, mandibles, projecting toward its center in front. These spines are $.18 \mathrm{~mm}$ in length and $.15 \mathrm{~mm}$ wide at the base where the muscle attachment occurs. From near the base they suddenly narrow into a sharp pointed spine which is chitinous at tip and brown in color. These are used for piercing the outer wall of the scale and for holding it in place while the fluids are sucked from the body.

"The pupa is yellow in color, with ocelli and eyes reddish. [About 24 hours prior to the eclosion of the adult the eyes become green.] Length $.75 \mathrm{~mm}$, width $.375 \mathrm{~mm}$. The adult appendages, enclosed in their sheaths, lie close to the body on the ventral side. Always accompanying the pupa are from six to ten black or dark brown torpedo-like bodies, $.125 \mathrm{~mm}$ long and $.055 \mathrm{~mm}$ broad [meconia] which are evacuations from the digestive tract and are expelled by the larva preliminary to pupation. [The pupa of the Chinese golden chalcid differs from the California by having a longitudinal blackish stripe on the venter.]

"This [adult] parasite does not always emerge through an exit hole in the scale, but very commonly simply pushes its way out from under the scale. The scale covering seems to be loosened from the surface in most cases so that this means of emergence is comparatively easy. This is further brought about by the movement of the parasite, and also because of the fact that the scale covering is always separated from the insect [scale body] and has a chance to loosen before the parasite is mature. In case, however, the scale covering is held securely to its resting surface the parasite eats out an irregular hole in the scale covering just beyond the molted skin in the case of female scales, and at the posterior third in the case of male scales. The parasite almost invariably is lying on its back as a pupa. Not infrequently two pupae are found under one scale, and one case has been observed where there were three.

"The egg is deposited under the scale covering, but either on the upper or lower side of the insect itself, most commonly on the lower. It is not inserted within the body of the insect. Preliminary to oviposition a thorough examination is made of the scale by alternately tapping with the antennae from the center of the scale to the periphery. Upon reaching the edge of the scale a rapid backward movement is made, at the same time turning slightly around so that the entire surface is explored by the antennae in from five to eight backward and forward movements in a remarkably short time. This procedure may occur with but one scale before the ovipositor is inserted, and again a dozen or more may be gone over without finding a suitable scale for oviposition. But the parasite does not rely alone on the exploration with the 
antennae, for the ovipositor may be inserted many times without any eggs being deposited. Insertion with the ovipositor may occur with the insect beneath in various conditions, and not infrequently it is dead and shriveled up. But exploration by the ovipositor is the final reliance for the placing of the egg.

"The ovipositor is not inserted under the scale covering, but through it just beyond the insect beneath. The parasite is facing away from the scale during oviposition so that the ovipositor is pushed down and backward toward the center of the scale.

"A specific case will serve to illustrate the behavior during oviposition. Parasite inserted ovipositor and laid egg in scale No. 1 occupying five minutes. One insertion was made in each of three other scales occupying from one to three minutes each. No eggs deposited. In scale No. 5 ovipositor inserted eleven times, and remaining in scale as follows : 1 min.; 3/4 min.; 1 min. ; $13 / 4$ min. ; 1 min. ; 1 min.; $11 / 4$ min. ; 1 min. ; $3 / 4$ min. ; $11 / 2$ min. ; $63 / 4$ min. Scale lifted and but one egg deposited, this undoubtedly at last insertion.

"Eggs may be deposited under scales of various stages as follows : Female between first and second molt and between second molt and egg laying. Male after first molt, prepupa and pupa. In no case has a larva of the parasite been seen with a scale during the molting periods or during the egg-laying period. The scale during these periods is very different than at other times. The body wall is hard and glassy, while the contents are more fluid and the insect adheres firmly to the scale covering. Between the molts the body wall is flexible, is not so distended by the body fluids, and the scale covering very readily separates from the insect itself. This last point accounts for the readiness with which the covering is lifted in many cases to allow the escape of the parasite.

"The fact that the parasite has not been seen infesting a scale during the molting periods or the egg-laying stage is accounted for because of the checking in growth of the scale. So far as our observations have gone, eggs are not deposited under scales in these conditions. The effect of the parasite on the host seems to be the only explanation for the fact that molting may not occur later, and before the parasite has developed. The feeding of the parasite larva seems to check the development of the scale as soon as it is attacked, or soon thereafter."

Charles Fleschner (unpublished notes) observed a female deposit 4 eggs on red scale during a period of 15 minutes.

In order to produce its full complement of eggs the adult must include protein in its diet. This it does by feeding on the body fluids of the scale when the latter is in the host condition, that is, during the third stage before the scale body is in close contact with the seale cover. To bring the body fluids out through the scale cover, the parasite constructs a waxen pipette from the scale cover to the scale body underneath. The construction of the pipette by the golden chalcid was first observed and described by Charles Fleschner (unpublished notes).

Early in 1943, Glenn Finney (unpublished notes) noted that the adult golden chalcid had the habit of destroying many red scales without either feeding or depositing eggs upon them. This habit, which is characteristic of 
certain parasites, had been observed previously with Metaphycus helvolus and Comperiella bifasciata (Flanders, 1942; 1943). When populations of first- and second-stage red scale on squash were exposed to large numbers of golden chalcid the destruction of the scale was complete, neither the host nor the parasite reproduced.

In order to obtain more information concerning this "mutilation" phenomenon, Dr. I. Crouzel, an Argentine entomologist, temporarily working during the summer of 1944 under the direction of Professor Harry S. Smith, was assigned the problem. Data were obtained (Crouzel, 1944; unpublished notes) on the behavior of several hundred females in relation to red scale of different stages infesting grapefruit. It was noted that the female had the habit of destroying immature red scale by thrusting its ovipositor into the scale body and by extensive probing, mutilating the viscera. A female would work over a scale for as long as 15 minutes, inserting and withdrawing its ovipositor many times. For a considerable period before the attacked scales collapsed and dried out they exhibited characteristic reddish blotches. Crouzel concluded that each parasite during its adult life is capable of thus destroying 40 or more scales.

In one experiment to test the preferential mutilation reaction of the golden chalcid to different stages of the host, 125 gravid females were confined for 24 hours to 6 grapefruits infested with 6 ages of scale. The infestations developed at $80^{\circ} \mathrm{F}$ and were held until the effects of mutilation were observable. The data thus obtained by Crouzel are tabulated below:

\begin{tabular}{|c|c|c|c|}
\hline & Stages of scale & $\underset{\text { scale }}{\text { Number of }}$ & $\begin{array}{l}\text { Per cent of kill by } \\
\text { golden chaloid }\end{array}$ \\
\hline First stage & $\left(\begin{array}{l}3 \text { days old } \ldots \ldots \ldots \ldots \ldots \ldots \ldots \ldots \ldots \ldots \ldots \ldots \ldots \ldots \ldots \\
8 \text { days old } \ldots \ldots \ldots \ldots \ldots \ldots \ldots\end{array}\right.$ & $\begin{array}{l}194 \\
154\end{array}$ & $\begin{array}{l}28.35 \\
75.16\end{array}$ \\
\hline Second stage & 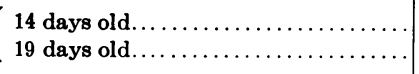 & $\begin{array}{l}280 \\
217\end{array}$ & $\begin{array}{l}46.78 \\
25.25\end{array}$ \\
\hline Third stage & 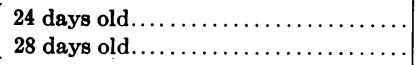 & $\begin{array}{l}250 \\
354\end{array}$ & $\begin{array}{l}4.40 \text { (male scale) } \\
\text { None }\end{array}$ \\
\hline
\end{tabular}

The mutilation activity of the golden chalcid is not restricted to its host; the immature stages of the parasite itself, particularly the pupal stage, are subject to attack. The failure to recognize fully the detrimental effects of this habit caused considerable delay in the development of a practical and economical method of mass-producing the golden chalcid.

The Chinese Species. The Chinese species differs from the California form in being usually biparental. On third-stage hosts the sex ratio is predominantly female, whereas on second-stage hosts the male predominates. It successfully attacks more species of scale insects and inhabits a greater environmental range than does the California form. When the two species are in competition with each other, the Chinese species becomes dominant, possibly because its mutilation habit may be more highly developed. The Chinese golden chalcid is positively anemotropic. This does not appear to be true of the California golden chalcid. 


\section{CRITICAL FACTORS AFFECTING MASS CULTURE OF HOST AND PARASITE}

Host-parasite Relations. The successful parasitization of the red scale occurs only when the body of the scale is not attached to its cover. This is the situation during the second stage with gray margin, the third stage with gray margin, and the prepupal male stage (fig. 3a). The red scale in all other stages is not a true host of the chalcid. This restriction of parasitization, together with the chalcid's habit of mutilating the scale during any of the growth stages, makes necessary short periods of exposure to limited numbers of chalcids. Such exposure is attained by the introduction of host populations into a parasitic population which is constant in numbers (Flanders, 1949).

In this type of entomophagous culture the segregation of the emerging adult population from the parasitizing population is essential in order to control production and to make efficient use of production material.

In the mass culture of any entomophagous insect the inherent reproductive capacity of the individual is rarely if ever realized, being an attainment which is, as a rule, not compatible with efficiency of operation.

Under the most efficient mass culture conditions the red scale is exposed to attack only during the mating period of the third-stage female. Although the chalcid develops successfully on the gray second-stage scale and on the prepupal scale its use is not economical since: 1 ) the adult parasites from such host stages emerge at a time when the parasites of the gray third stage are in the prepupal and pupal stages and subject to multilation ; 2) a relatively high proportion of scale is mutilated when in the second stage; and 3) when a female scale is parasitized while in the second stage it yields only 1 small parasite, whereas if parasitization had been delayed until the scale had attained the third stage, it would have yielded either 2 or 3 parasites or a large single one. A large parasite has a greater egg-producing capacity than a small one.

The handling of a host such as a diaspine scale insect is a relatively simple procedure since the female is sessile at all times except for a few hours after birth. In the handling of the parasite, however, the adults must be kept confined in order to accomplish maximum parasitization and to facilitate collection for release in the field. The optimum host-parasite ratio may vary with the amount of space, the amount and distribution of daylight, the amount of scale, and the type of host-infested plant material. The optimum ratio for any set of conditions is determined by trial and error. The increase in females per generation should be at least threefold.

The use of a series of small parasitization units, such as those employed in the culture of Macrocentrus ancylivorus (Finney, Flanders, and Smith, 1947 ), is not economical in golden chalcid production, particularly when the inocula are bisexual with sex ratios not readily ascertained. Such units require the use of a much larger inoculum of parasites than a large single parasitization unit of a size sufficient to contain the parasitized infestations for the period of parasite development. From such a unit the parasitized scale can be removed without loss of the parasitic inoculum, an inoculum having a sex ratio which is practically constant. Maximum reproduction per female is 
thus obtained. By manipulation of the tropic responses of the parasites, the inoculum in a large unit is concentrated in the host infestation area. Such responses also facilitate feeding the parasites with honey. A large unit therefore serves a triple purpose : in addition to obtaining parasitization, it provides space sufficient for the storage of parasitized infestations prior to emergence of the adult parasites, and conserves the inoculum.

In Macrocentrus production the parasitization units served as infesting units. This resulted in a saving in labor and equipment, which counterbalanced a loss of about 75 per cent in the reproduction capacity of the inoculum.

Host Mutilation and Feeding. The culture of parasitic Hymenoptera that must feed on the body fluids of their hosts in order to obtain the material needed for the development of their complement of eggs is complicated by the associated phenomenon of predatory mutilation. Mutilation, that is, the serious injury of the host's viscera by extensive and prolonged probing with the ovipositor, is a necessary prelude to feeding on the host's body fluids. Such feeding, however, does not always follow mutilation.

When the parental parasite population is excessive in relation to the available host population, the mutilation activity of the parasite may destroy the entire culture of host and parasite. In mutilated infestations many collapsed Aphytis eggs may be found close to the dried-up bodies of the scale. To reduce mutilation to a minimum and at the same time attain a maximum of successful oviposition, it is necessary to maintain a certain ratio between the populations of parasite and its host. The number of parasites used to inoculate a given infestation of scale must be determined experimentally for each set of conditions. With an excess of parental stock, the mutilation effect may extend to the prepupae of the parasite itself. It is advisable to collect the adult parasites within 24 hours after they emerge. Otherwise, they may cause a considerable mortality of the remaining prepupal and pupal stages. Aphytis is very destructive to pupae of other parasites of red scale.

Spoor Effect. Premature exposure of scale infestations to Aphytis has seriously interrupted production. This occurs when the infestations upon being placed in the parasitization room consist of scale either in the second molt or in the sexually immature early third stage. Parasitization of such infestations when the scales attain a developmental condition suitable for oviposition by Aphytis will be low. This inhibition of oviposition may be, in part, an effect of the spoor of Aphytis-the spoor that accumulates on the scales as the females move over them in their search for suitable hosts. The apparent discrimination on the part of the female between contaminated and uncontaminated hosts may be conditioned by prior oviposition in suitable hosts.

A spoor effect was described by Salt (1937) in the case of the egg parasite Trichogramma. Salt found that the gravid female in walking on a host temporarily contaminates it with an odorous chemical (probably from the tarsal glands), which tends to inhibit oviposition in it by other Trichogramma females.

If the accumulated spoor is responsible for the inhibition of oviposition by Aphytis in a prematurely exposed infestation its effect on such infestation may possibly be obviated by removing the infestation from the parasitization room for about 24 hours. 
Regulation of Temperature. Temperature is used to regulate the activity of insects. In order to obtain maximum production of the golden chalcid, these temperatures should be such that the reproduction rate, that is, generations per month, is at a maximum and the turnover of material most rapid. Temperatures between $80^{\circ}$ and $85^{\circ} \mathrm{F}$ have proved suitable for efficient golden chalcid culture. Having established the optimum temperature, it must be held constant so that a daily routine can be followed according to a set schedule which will permit the most efficient use of labor and equipment.

Regulation of Humidity. Relative humidities above 50 per cent are essential for the propagation of both host and parasite. In propagating red scale, humidities should exceed 70 per cent. Maximum production of crawlers occurs only under such conditions. Humidities of about 30 or 40 per cent are lethal to red scale during the first molt period. At low humidities many scale crawlers are unable to get out from under the scale cover of the mother. The development of red scale is most rapid and deviates least from the average when it is grown at 85 to 95 per cent humidities. At such humidities there is little if any difference in its growth rates on either citrus or potato.

The golden chalcid seems to be less sensitive to low humidities than its host. During development it is protected by the cover of its host. As a larva and an adult it obtains moisture by ingestion. Under mass culture the adults are fed undiluted honey. The maintenance of the honey in an edible condition, however, requires a minimum humidity of 55 per cent.

Qualifications of Host Plant. As pointed out above, a satisfactory host plant is one that is readily available and possesses a form and habit that permits ease in handling, the efficient transfer of infestations, and furnishes a large area of infestation per unit of space occupied by the host plant. The host plants of red scale that have been found to meet these requirements are citrus fruits and potato. The fruits of citrus (particularly grapefruit) and the tubers of potato (White Rose) when mature are satisfactory laboratory hosts. The grapefruit should be about 3 inches in diameter, the potato tuber about $11 / 4$ inches. Infestations of red scale on egg-sized potato tubers serve most satisfactorily as a source of scale since the tuber holds up under infestation much longer than any citrus fruits. Consequently, the potato is the standard medium for mother stocks of red scale. Disease-free tubers will hold up under heavy infestations of red scale for 3 or 4 months, then will gradually dry out, first becoming leathery and then brittle. Potatoes predisposed to disease usually become rotten within 25 days after being infested.

Red scale growing on potato is readily parasitized by such parasites as Habrolepis rouxi Comp., Comperiella bifasciata How., Aspidiotiphagus lounsburyi (B. and P.), Prospaltella sp., and Aphytis n. sp. "A." The California golden chalcid, however, does not parasitize red scale on the potato as readily as it does red scale on citrus. Possibly this is because in the formation of the scale covering, particles of potato skin are incorporated in it, lessening its attractiveness to the parasite. Grapefruit is less subject to desiccation than lemon fruits and is preferable for supporting parasitized infestations in spite of the large size and consequent few scales per unit of space. Turgidity of citrus fruits is prolonged if the stem end is dipped in paraffin wax. Under high humidities, waxing usually is unnecessary. 
The most satisfactory type of potato is the flat, smooth-skinned White Rose. Red scale crawlers settle more readily on the smooth-skinned potato than on the netted skin of the Russet potato. The flat type of potato is infested more efficiently than the round potato. The grapefruit (or potato) when used to support parasitized infestations of red scale is utilized within a period of 50 days after traying and fumigation ( 2 days preinfestation to allow methyl bromide to dissipate, $21 \pm$ days of scale development to host size, $15 \pm$ days for parasite development, and $10 \pm$ days for completion of parasite emergence).

The potato stock used for red scale production should be grown and handled in the manner commercially used for seed potatoes, that is, in sandy loam free from potato-disease organisms and with a minimum amount of irrigation water to produce a small, firm tuber, thus eliminating the need for washing and grading.

The host plant (potato or grapefruit) should be completely infested within a 24-hour period and the density of the infestation should be uniform, that is, the scale evenly distributed over the surface of the plant. All scales in such infestations are then in the same growth stage. Red scales that are crowded develop less rapidly than uncrowded scales. The spatial distribution of scales on the host plant may influence parasitization. In general, the number of parasitized scales per unit area appears greater at medium scale densities. The developmental rates of the scales in each infestation must be about equal in order that the majority of the scales attain the host condition at the same time. Sprouting of the potato is inhibited if the initial infestations are sufficiently heavy.

There are four methods of transferring red scale to fresh host plants: 1) the contact method, which involves the temporary placement of the fresh host plant on top of the mother infestation so that the crawlers can move from one to the other; 2 ) the drop method, which involves the placement of the fresh host plant beneath the mother infestation, the crawlers dropping from the latter when unable to maintain a foothold because of crowding ; 3 ) the brush method, which involves brushing the crawlers from the mother infestation with a soft camel's hair brush (this method injures many crawlers) ; and 4) the blowing method, which involves the use of compressed air.

The blowing method for transferring scale is most efficient. With this method the losses resulting from migration, desiccation, and bruising are at a minimum. It is used economically only when the amount of mother infestation equals or exceeds the amount for the use of which the equipment has been designed. Its use permits in minimum time complete, uniform infestation of the host plant with scales of equal size. This is a prerequisite of rapid utilization of material and the quick turnover so necessary for efficient production.

Red scale tends to establish itself (settle down) on citrus fruits more quickly than on the potato tuber; consequently, the transfer of newly hatched scale (crawlers) from parent (mother) infestations occurs more readily when potatoes are used. This is particularly true when the transfer of crawlers is made by either the contact method or by the drop method. Many crawlers settle down within an hour and begin the construction of white 
caps of wax. The point of settlement usually is at or near the point of primary contact. When transfer of crawlers is made by either dropping, brushing, or blowing, the primary contact is on the top surface of the host plant. Consequently, in order to completely infest the host plant it must be turned 180 degrees.

Unlike soft scales and mealybugs, red scale in the crawler stage is not strongly phototropic; it exhibits positive phototropism in a relatively weak degree. It is negatively geotropic to the extent that newly hatched crawlers accumulate on the top side of fruits. This fact facilitates their transfer by compressed air. The proportion of the crawlers moving to the top side of the potato increases as the density of the scale infestation increases. The diurnal increase in light intensity stimulates emergence of crawlers from under the parental scale covering. This concentrates the emergence of crawlers to daytime hours so that the transfer of crawlers is most efficient at maximum intensities of daylight.

Collection of Release Material. With red scale and Aphytis the use of self-perpetuating populations combined in automatic parasite-collecting units is not feasible because of the mutilation activity of the parasite and its relatively weak geotropic and phototropic responses. Under certain conditions, however, these responses may be economically used to collect the parasites automatically. Such conditions occur: 1 ) when the parasitized host population lacks stages attractive to the parasite (a situation which occurs with red scale and Aphytis when the scale population consists of individuals equal in age and the parasitized population is placed in a separate unit for emergence of adults) ; 2) when the housing of this parasitized host population is such that the population is situated away from an illuminated area of high light intensity relative to the rest of the unit (the source of light being located above and to the side of the parasitized host population); and 3 ) when the parasitized host populations are placed in the unit in succession so that the number of parasites emerging and concentrating in the release container each day is fairly constant.

From the standpoint of providing material suitable for field releases to control low populations of a pest, automatic collections may not be economical. This would be the case if the parasites are to be released in relatively small amounts at intervals. Collection for this type of release involves either the use of many small emergence units or the hand segregation of automatically collected parasites into small release containers.

With a parasite such as Macrocentrus ancyliworus which, after it has cocooned, can be separated from the remains of its host, the most efficient method of making field releases is to allow the parasite to complete its development and emerge in the field. With Aphytis it is not economically feasible to isolate the immature stages since the host remains attached to the food plant, and the parasite, which does not construct a cocoon, is small and delicate.

The release material can consist of the host plant bearing the immature parasite, but the extra time and additional equipment needed to get such material into the field and to protect it from predators until the emergence of the parasites is complete is likely to be more expensive than the labor and 
equipment involved in collecting the adult parasites in the laboratory and then releasing them in the field. Also, it is not advisable to place parasitized red scale populations in the field since such populations usually contain many unparasitized scales which will produce crawlers that are readily windborne.

The most practical means of obtaining Aphytis for release is to provide means for the automatic concentration of adults on a limited surface from which they are easily and quickly collected.

\section{HOUSING AND EQUIPMENT}

Housing Requirements. The building for housing the cultures of host and parasites should be located in a region having a climate characterized by relative humidities of less than 60 per cent during the.warmest weather, with a high proportion of sunny days throughout the year. The building should be insulated to permit the continual maintenance of $82^{\circ} \mathrm{F}$ at a minimum expense. The ventilation equipment should include an air washer to permit some control of humidity during cold weather and prevent excessive accumulation of heat during the summer. The air inlet duct of each room should contain a thermostatically controlled heater. The air inlets and outlets in the production room should be in the walls at floor level for minimum stratification of room temperatures.

The room used for scale transfer should have three sides of glass to attain the fullest effect of daylight on emerging scale crawlers. The rooms used for parasitization and parasite emergence should have two sides of glass, one with east and the other with west exposure to obtain the maximum amount of sunlight in the collection of Aphytis. Windows are not needed in the rooms used for holding the scale during its development. All windows should be of double glass with an air space between (the two pieces of glass) to minimize the amount of moisture condensation during cold weather. It is desirable for the ceiling of each room to be between 6 and 7 feet in height and flush with the top of the window glass to eliminate the blind area to an operator standing in front of the window collecting parasites. The ceilings of the rooms should be light colored, very smooth and hard surfaced to facilitate collection of parasites. Each room should be provided with electricity, water, air pressure, and vacuum connections. All rooms need to be insect-proof, particularly against ants. The windows should be covered outside with adjustable aluminum Venetian blinds, to provide regulation of lighting within the room (see fig. 2). The air compressor needed should have the capacity to maintain constantly the air pressure necessary for the transfer of scale.

A cellar should be provided for the temporary storage of potatoes. When potatoes are to be held longer than 2 weeks, the facilities of a commercial potato-storage plant should be used.

The rooms necessary for host-parasite production are as follows :

1. A room large enough for storing potatoes for at least 2 weeks and for housing the facilities for trayed potatoes (fig. 5) or other plant material (fig. 6). 


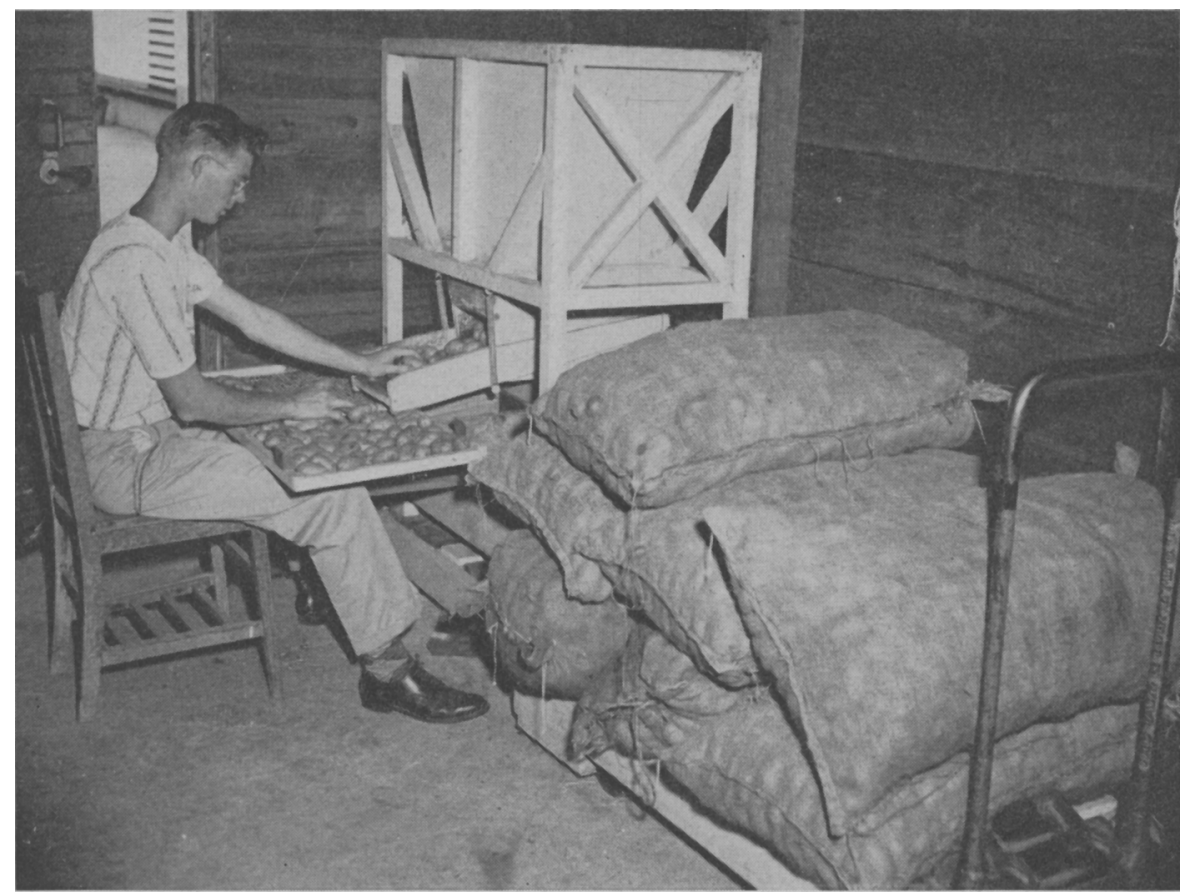

Fig. 5. Potato storage and sorting room. The potatoes are placed in single layers on hardware cloth trays. A hundred-pound sack of potatoes will fill five trays.

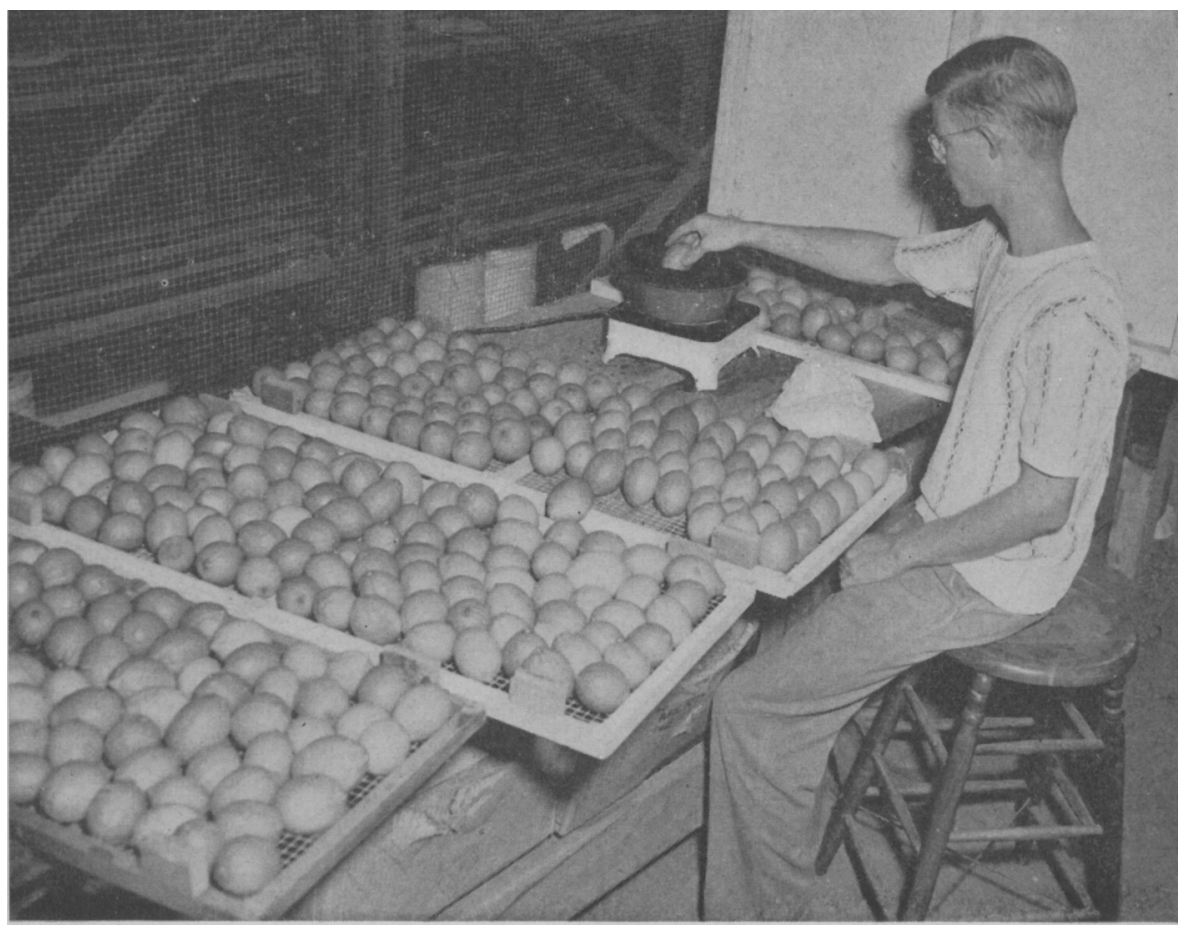

Fig. 6. Dipping stem end of lemon in hot paraffin to retard desiccation after infestation with red scale. 
2. A small room for fumigating potatoes with methyl bromide (figures 7 and 8 ).

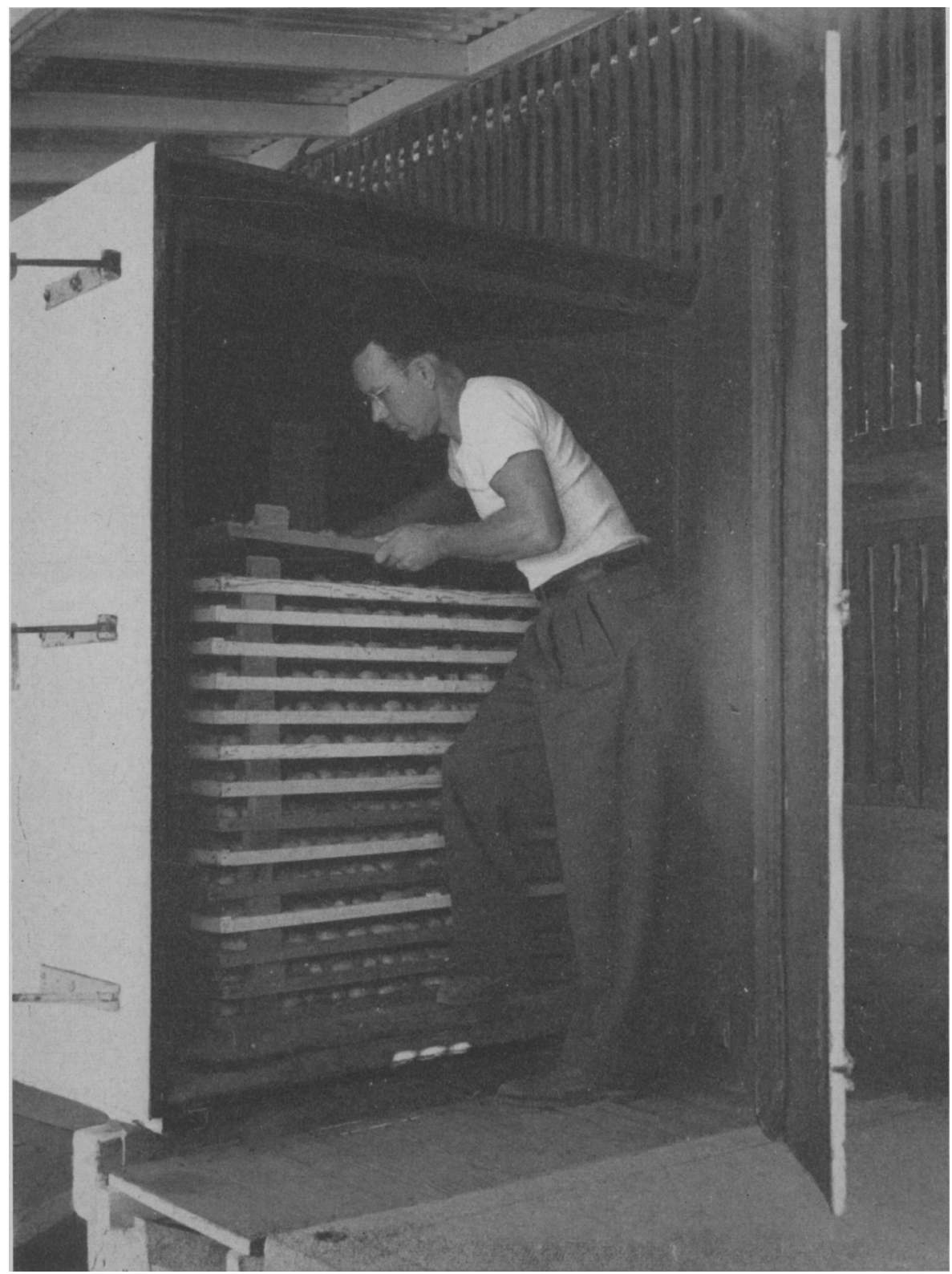

Fig. 7. Interior of fumigation box. The trayed potatoes are exposed to $55 \mathrm{cc}$ methyl bromide for 2 hours at $80^{\circ} \mathrm{F}$. 


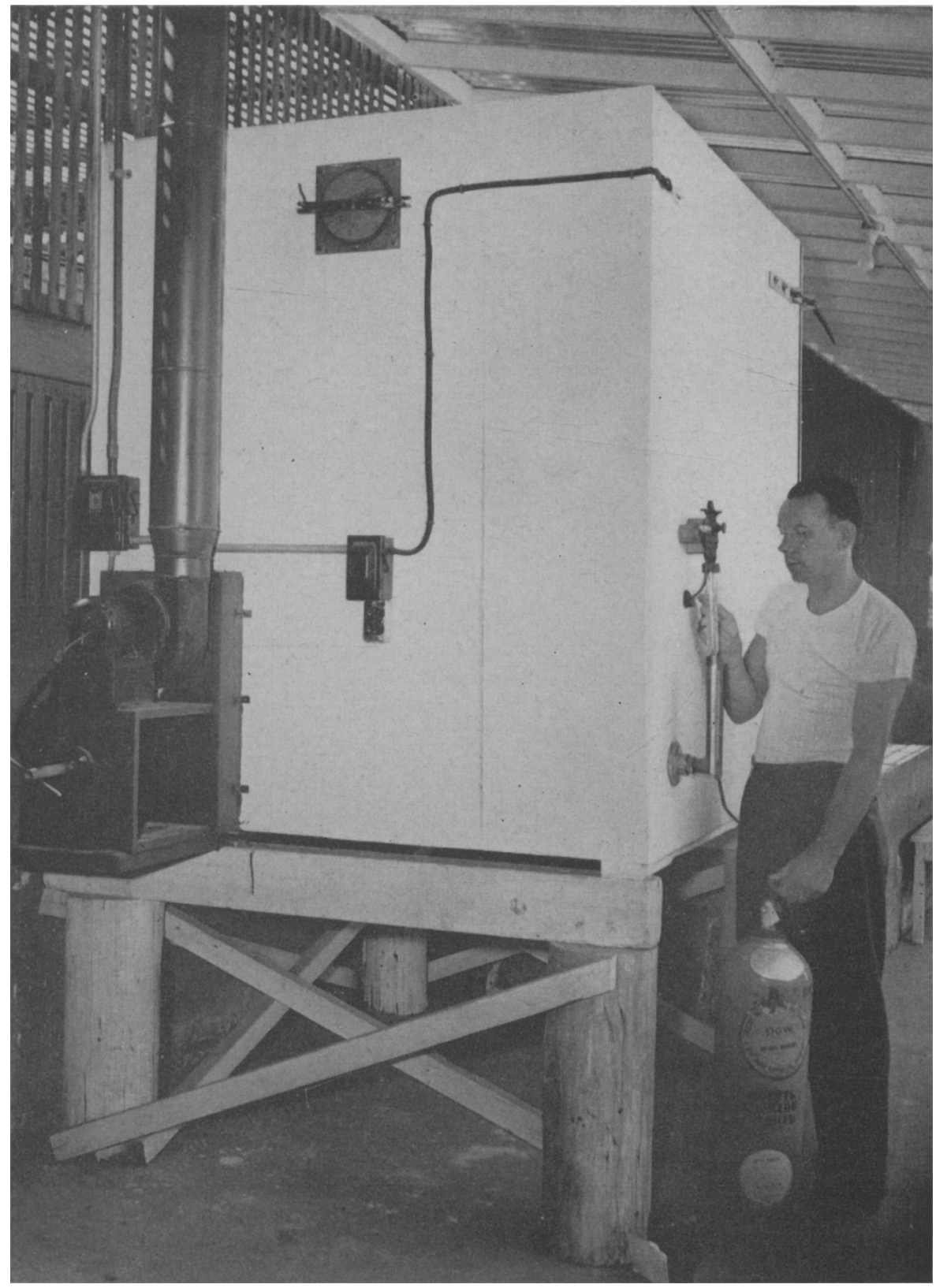

Fig. 8. Exterior of fumigation box (rear view). Note air suction pump and motor for clearing box of gas. A circular air intake aperture is located in upper part of box. A circular air outlet aperture is located at bottom of box under suction pump to which it is connected by a rectangular duct. The fumigation box contains a thermostatically controlled electric heater and an electric fan which are set in operation by means of an outside switch. The gas injector and thermometer below it are shown immediately in front of operator. 
3. A small room for holding potatoes for 2 days to permit dissipation of fumigant from the potatoes.

4. A room for infesting potatoes. It should be sufficient in size to hold the infestation being used as mother stock as well as the scale transfer equipment (figures 9,10 , and 11 ).

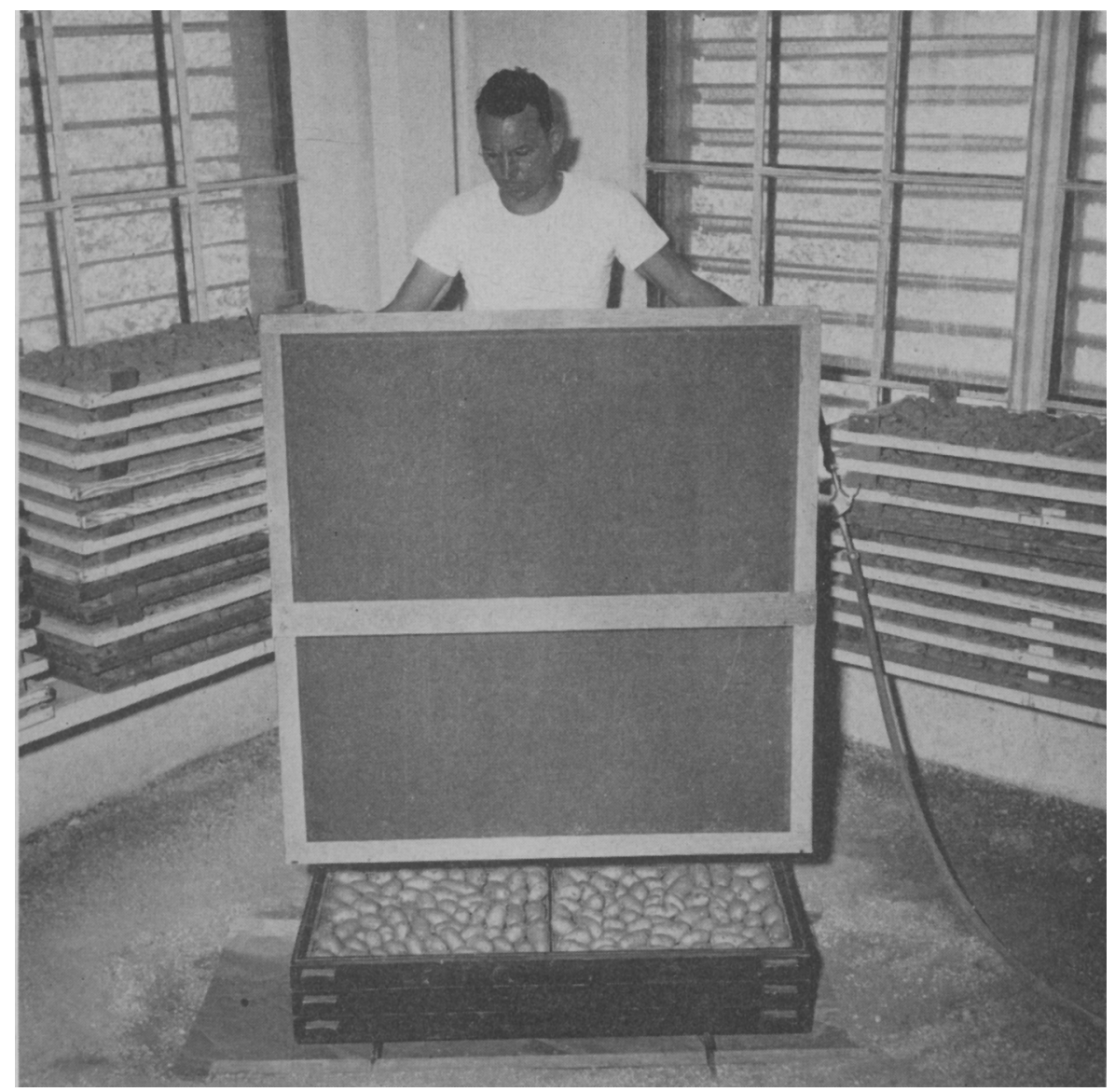

Fig. 9. Scale transfer hopper (open top and bottom) being placed over three layers of fresh potatoes in infesting frames in preparation for removing newly hatched scale from "mother" infestations in trays stacked in front of windows.

5. A room (or series of rooms) for holding the infested potatoes while the scale develops to host size (figures 12 and 13).

6. A room for the parasitization of host scale. This room holds all the racks and trays having infestation of scale suitable for parasitization ( 3 racks and 36 trays on the basis of 30,000 female parasites of Aphytis sp. "A" per day) (fig. 14).

7. Room for emergence of parasites. This room holds all the trays from which parasites are emerging (fig. 15). 
8. A room for preparing and handling parasite release equipment (figures 16 and 17 ).

9. A room or shelter for storing and repairing equipment, such as trays and racks.

10. A room for holding reserve mother stocks. The temperature of this room should be held between $55^{\circ}$ and $60^{\circ} \mathrm{F}$.

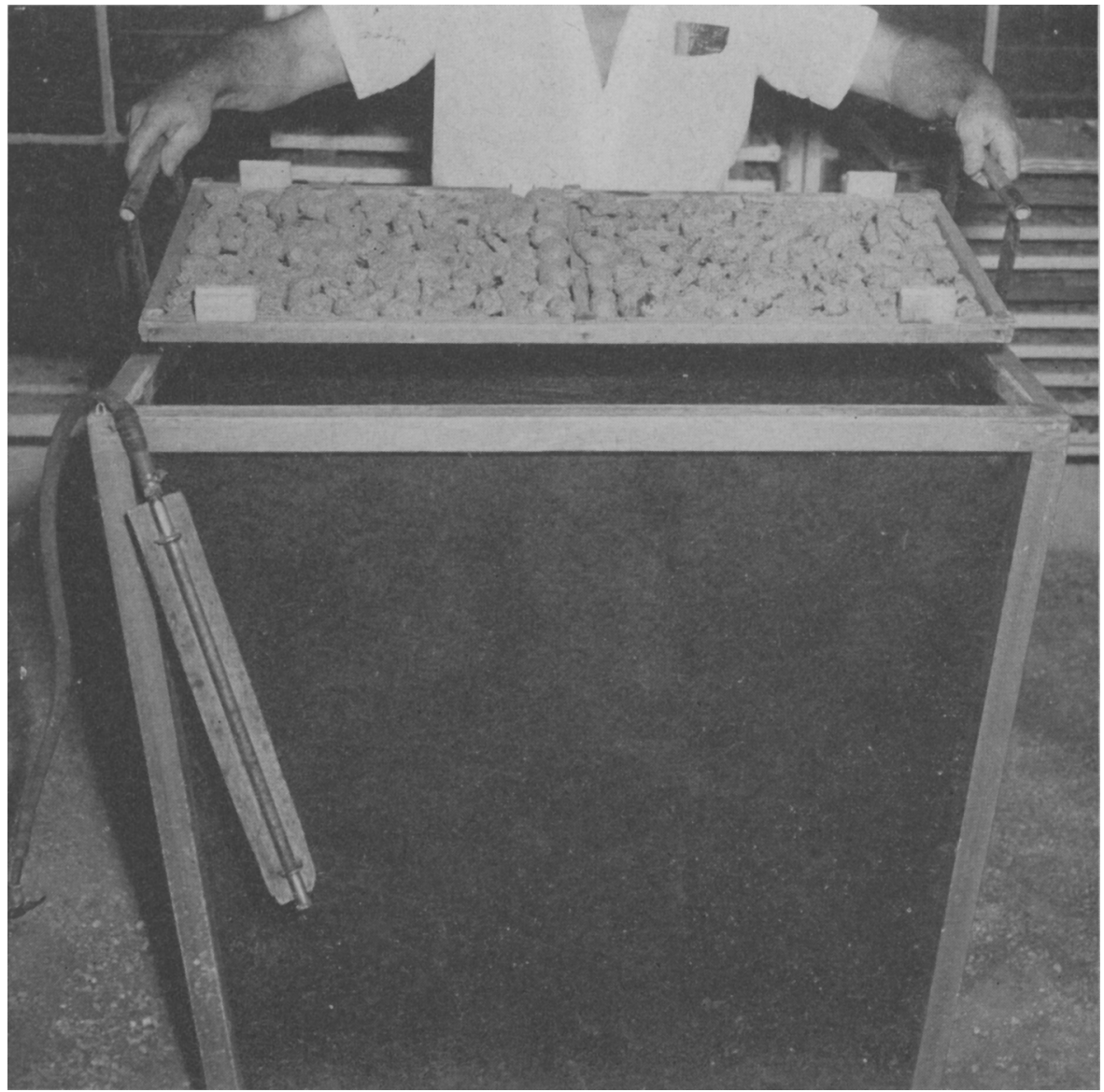

Fig. 10. Metal tray holders being used to set tray of mother scale inside top of scale transfer hopper. Note air brush consisting of a perforated brass tube fastened to a board for ease in handling.

Equipment Requirements. The specialized equipment for manipulating the materials used in host and parasite propagation should be standardized at the maximum sizes convenient to handle. The basic unit is the container for holding the host material. In the culture of red scale on potatoes or grapefruit this unit is the reinforced wire tray (see figures 5 and 7). All other equipment used in the sequence of operations should be correlated to measurements established by this basic unit. (If equipment is already on 


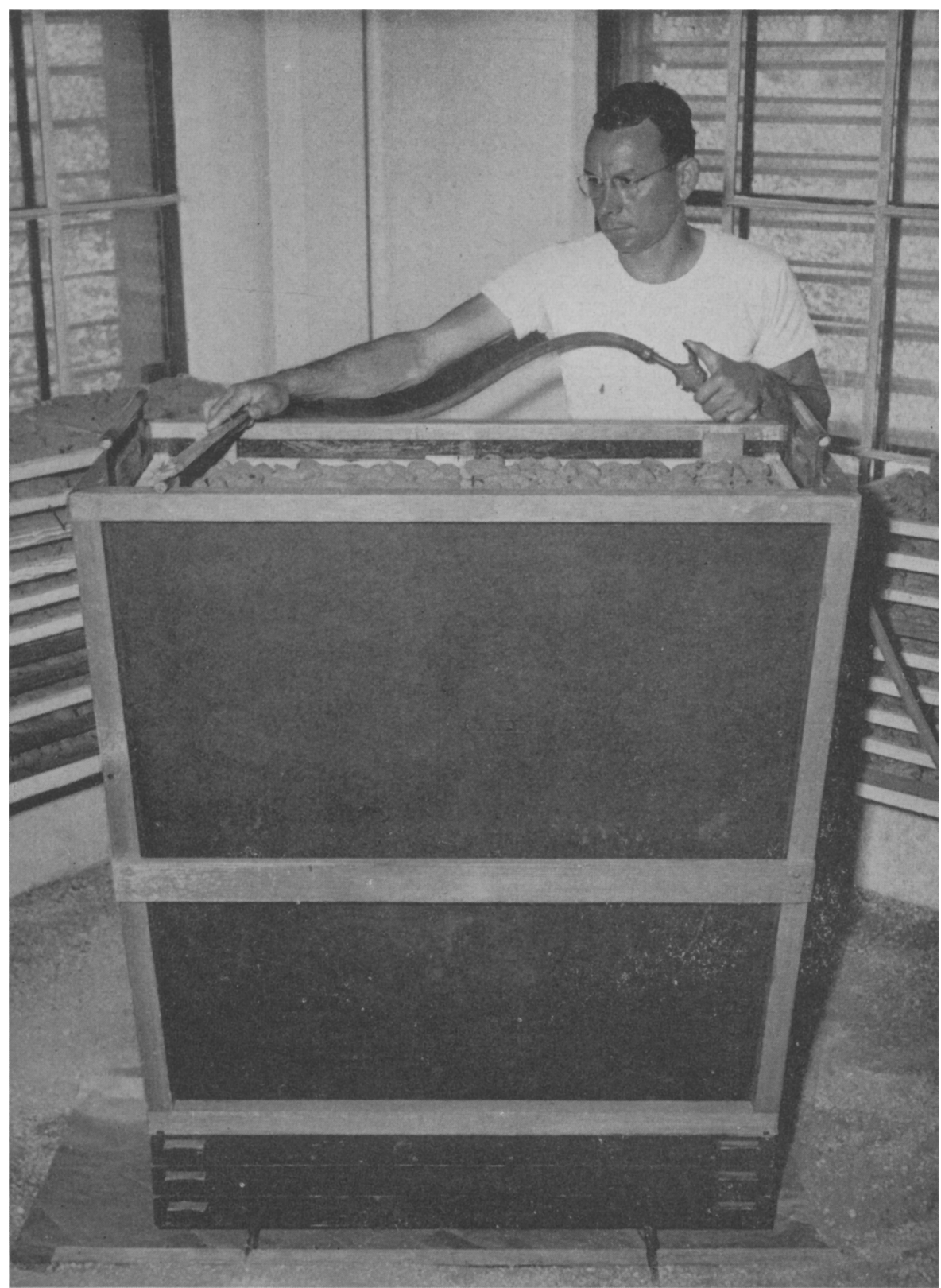

Fig. 11. Air brush being used to blow young scale from "mother" infestations to fresh potatoes beneath. The operator on opening valve in air line moves the air brush six times across the top of the tray of mother scale. Sheets of paper are placed beneath the layers of fresh potatoes in the frames to catch crawlers drifting through. 


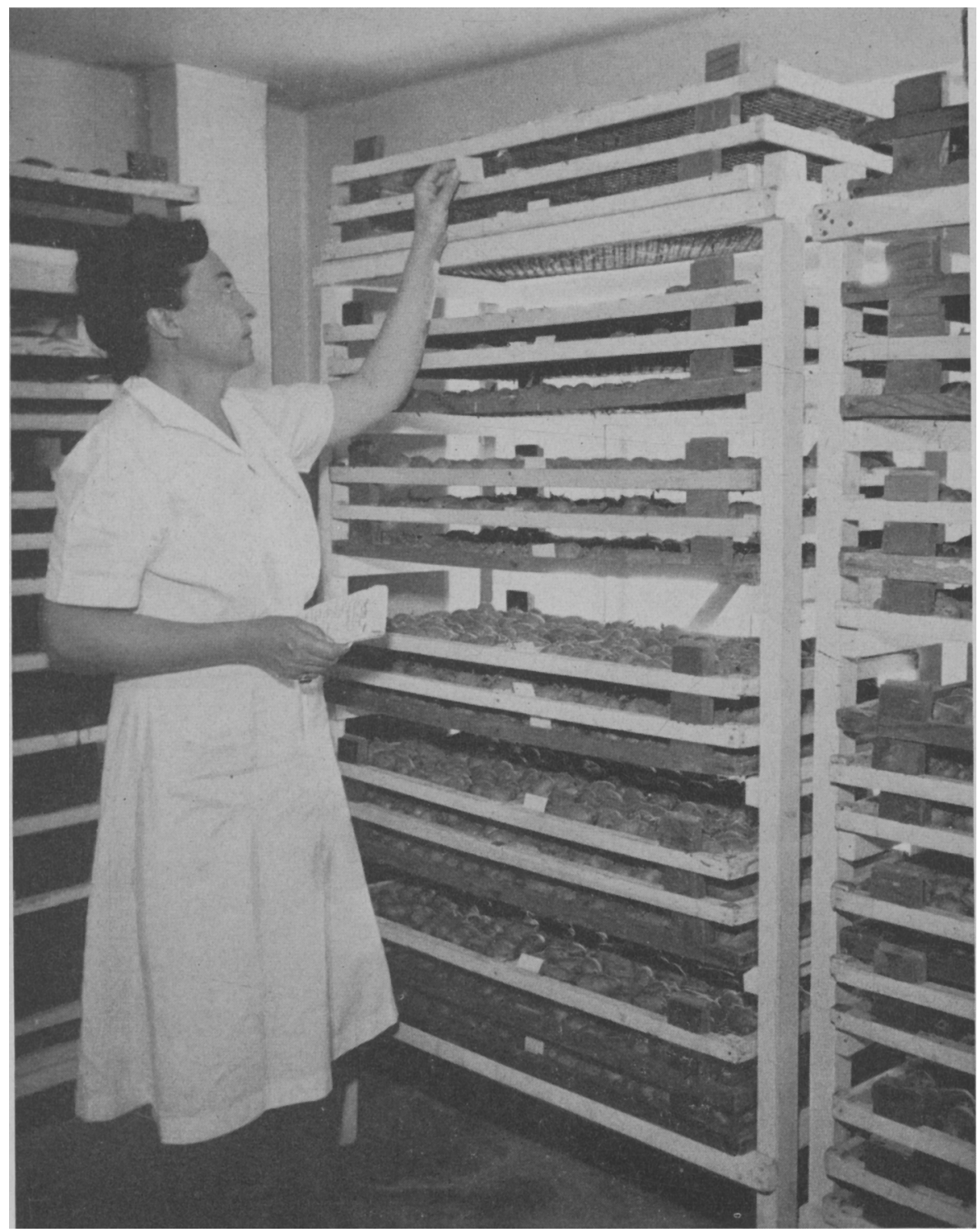

Fig. 12. Infested potatoes in holding room. Date of infestation is used as an indication of developmental stage of scale. Note trays arranged to be handled singly or in groups of three.

hand that could be efficiently used in the sequence of operations, the basic unit should be designed to conform with it.)

The design of the specialized equipment used in the culture of red scale and the golden chalcids in the University of California Division of Biological Control Insectary is described on the following pages. 


\section{The reinforced wire tray (the basic unit).}

This tray consists of a wooden (Oregon pine) frame with a narrow crosspiece at the center supporting a floor of $1 / 2$-inch-mesh hardware cloth. The outside dimensions are $40^{\prime \prime} \times 16^{\prime \prime} \times 1^{\prime \prime}$. A wooden tab is firmly fixed to the frame near each corner on the upper side to support other trays that may

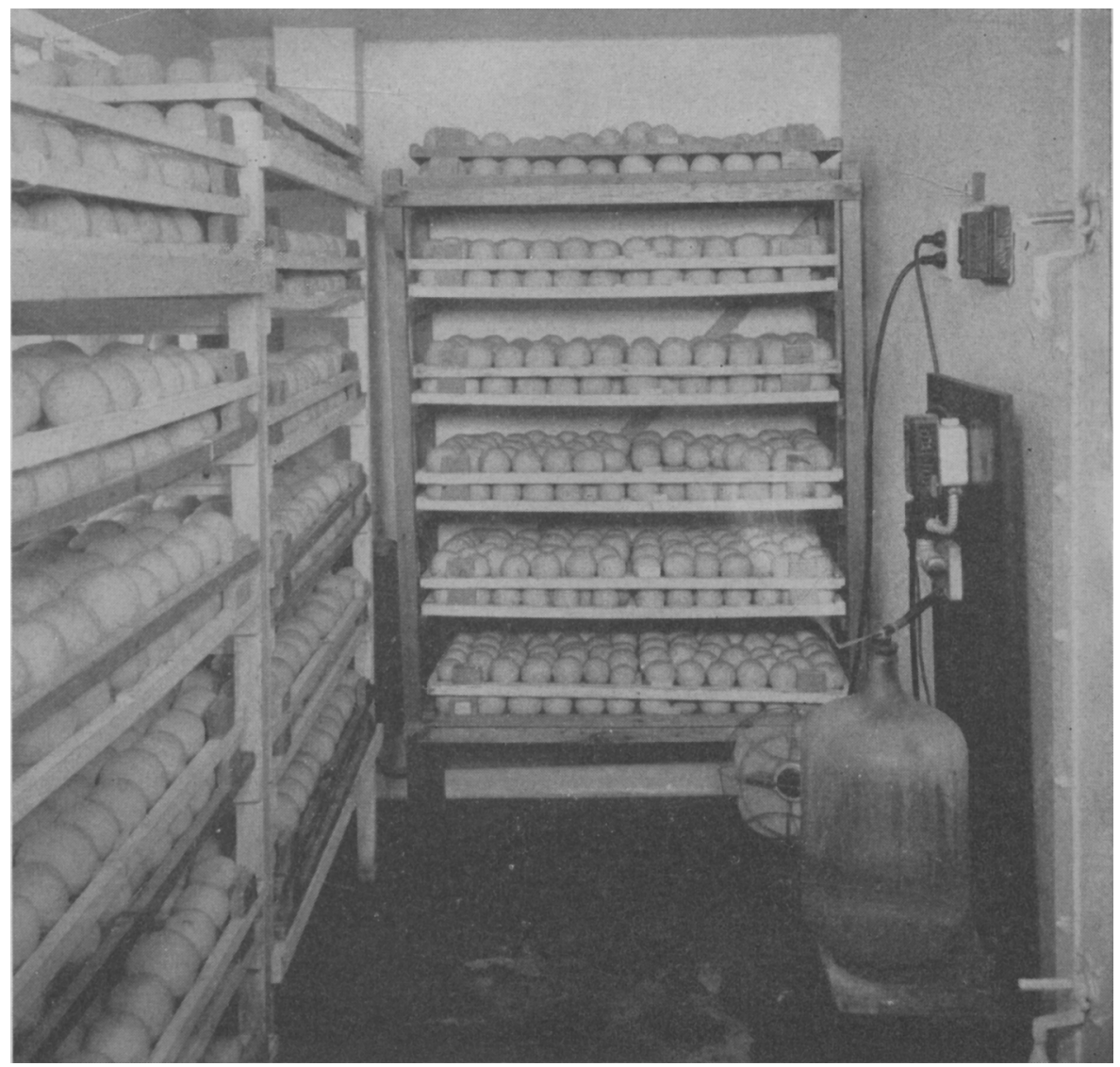

Fig. 13. Infested grapefruit in holding room. Note water atomizer and humidistat for maintaining a constant high humidity of about 90 per eent.

be stacked upon it. The top edge of this tab is half-lap, grooved to hold each supported tray in position, the upper edge of the tab being $21 / 2$ inches above the hardware cloth floor. When trays are stacked, the clearance between the floors of hardware cloth is about $3 \frac{1}{2}$ inches. The underside of the tray frame is half-lap, grooved to fit the grooves on the tabs of the tray upon which it is placed. This tray, which weighs about 3 pounds, will hold 21 pounds of egg-sized potatoes and 24 pounds of medium-sized grapefruit.

The use of tabs permits the handling of 2 trays of grapefruit or 3 trays of potatoes at one time. 


\section{The tray-holding rack.}

The rack is made of wood and constructed to hold 500 pounds of trayed potatoes. The over-all dimensions are $70^{\prime \prime} \times 43^{\prime \prime} \times 17^{\prime \prime}$. It is mounted on 4 metal casters with 3-inch wheels (fig. 16). The lateral runners for supporting the trays are 10 inches apart. Each set of runners holds 3 trays. This facili-

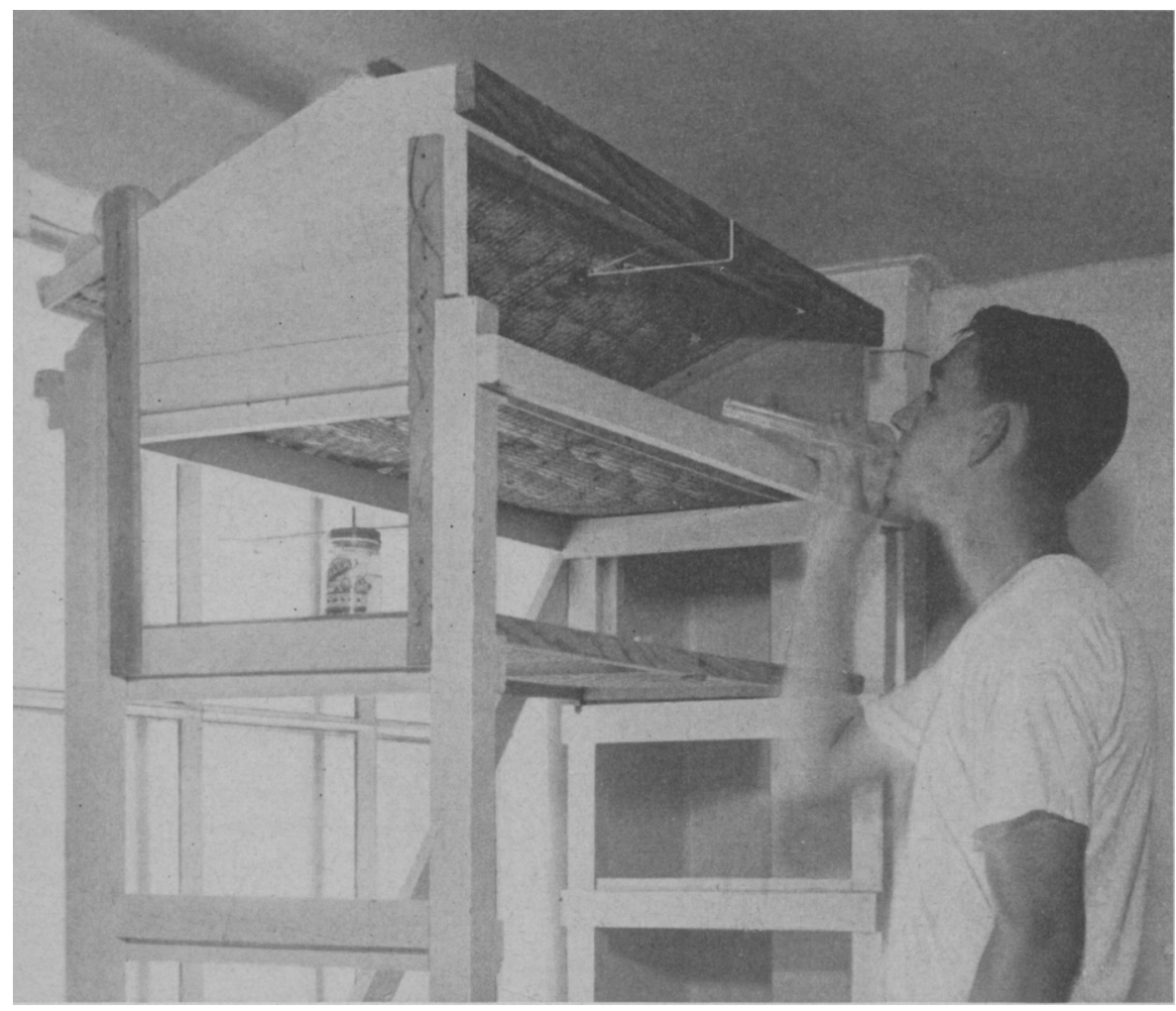

Fig. 14. Parasitization (sting) room showing position of scale-infested grapefruit when exposed to attack for two days in front of lighted window. Parasitized infestations are held in room for 10 additional days while parasites develop. Operator is adding the daily inoculum (2,000 parasites per fresh tray when only one half of grapefruit surface is infested).

tates handling since the 3 trays can be removed together or separately. The racks used in the parasitization room are modified so that the trays to be exposed to the parasites when placed on top of the rack are set at a 45-degree angle to the ceiling and window (see fig. 16).

\section{The transfer hopper, infesting frames, and infesting flats.}

In order to transfer the scale crawlers from mother infestations to fresh plant material by air blast, it is necessary to provide sufficient space below the mother infestation to prevent back pressure from the air blast carrying 
the scale crawlers away. This is accomplished through use of a tapered funnel or hopper (see fig. 11). When in use, a tray of potatoes infested with reproducing scale is set within the top of the hopper; the potatoes or grapefruit to be infested are placed in infesting frames and set below the hopper.

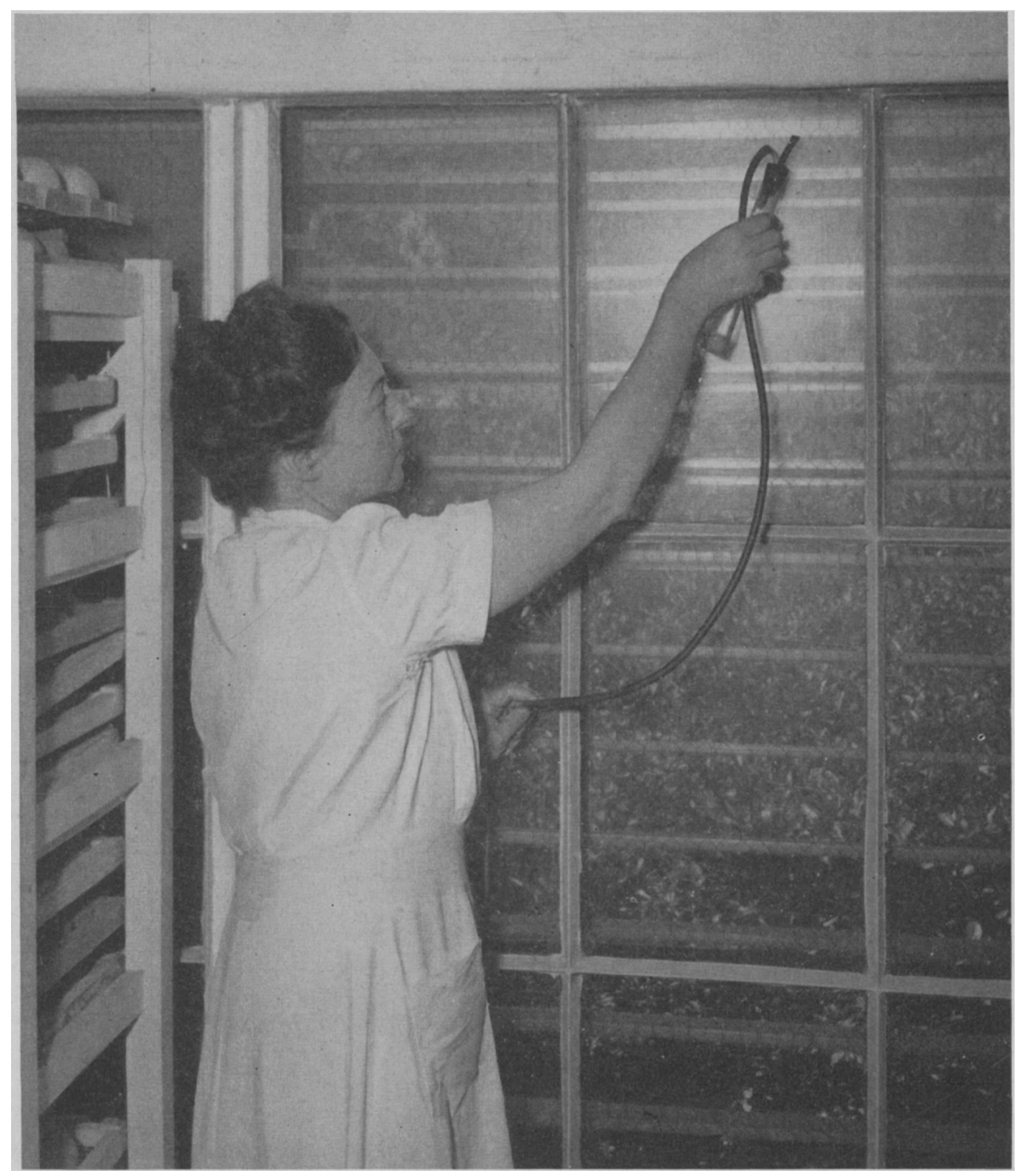

Fig. 15. Emergence room showing collection of parasites by means of an aspirator inserted in collecting tube.

The hopper is constructed of light-weight material with inner surfaces smooth. The dimensions are as follows: inside of top opening $17^{\prime \prime} \times 401 / 2^{\prime \prime}$, inside of bottom opening $131 / 2^{\prime \prime} \times 36^{\prime \prime}$, and vertical height approximately 43 inches. The ventral surfaces of the bottom rim are grooved to fit readily the half-lap edges of the infesting frames below (see fig. 9). 
Use of the infesting flats results from the fact that scale crawlers fix themselves to the potato at the point of first contact. In order, therefore, to infest the potatoes completely it is necessary to turn them. The infesting frames are made with solid sides to prevent the lateral movement of air during infesting (fig. 18). Each infesting frame is constructed to hold 2 removable infesting flats of $1 / 4$-inch hardware cloth. Each flat is supported when in the frame

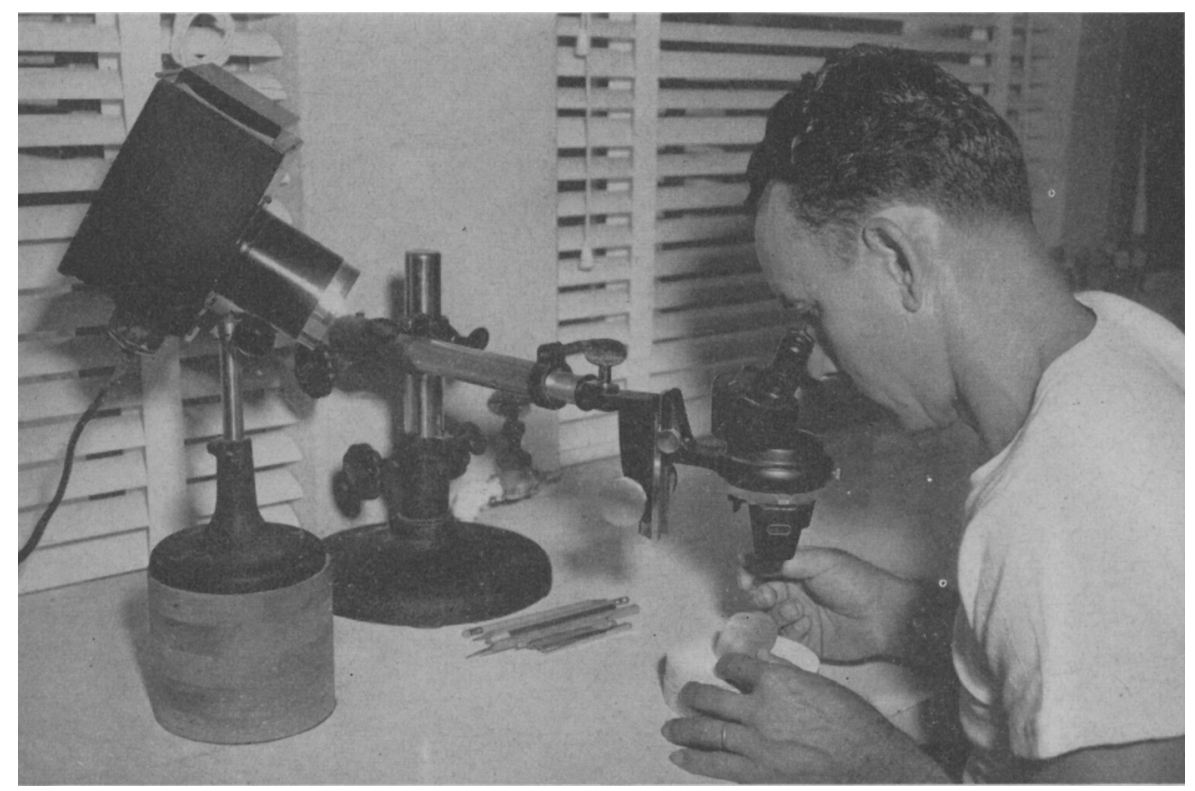

Fig. 16. Using microscope in order to ascertain the suitability of scales for parasitization. As soon as the scale cover can be lifted free of the third-stage scale, it is suitable for attack by the golden chalcid.

by 3 crossrods $1 / 8$ inch in diameter, inserted in the sides $1 / 4$ inch above the bottom. The top and bottom edges of the frame are cut with half-lap so that when stacked they do not slide out of position.

The dimensions of the frame conform with the trays and funnel and are as follows : outside measurements, $163 / 4^{\prime \prime} \times 39^{\prime \prime} \times 21 / 4^{\prime \prime}$ (with half-lap inside $\left.21 / 2^{\prime \prime}\right)$. The infesting flats are made entirely of $1 / 4$-inch hardware cloth (18gauge wire), with outside dimensions of $15^{\prime \prime} \times 181 / 2^{\prime \prime} \times 3 / 4^{\prime \prime}$.

\section{The air brush.}

The air brush (see fig. 10) consists of a $1 / 2$-inch brass pipe closed at one end and having a single row of $1 / 25$-inch openings $1 / 2$ inch apart along the entire length. The compressed air hose connected with the air brush is provided with a Dia. U. blow gun valve No. 212 (see figures 9 and 11).

\section{Tray holder.}

Two metal tray holders or handles $\left(13^{\prime \prime} \times 6^{\prime \prime}\right)$ are needed to carry the mother trays to the transfer hopper and to hold the trays in position in the 


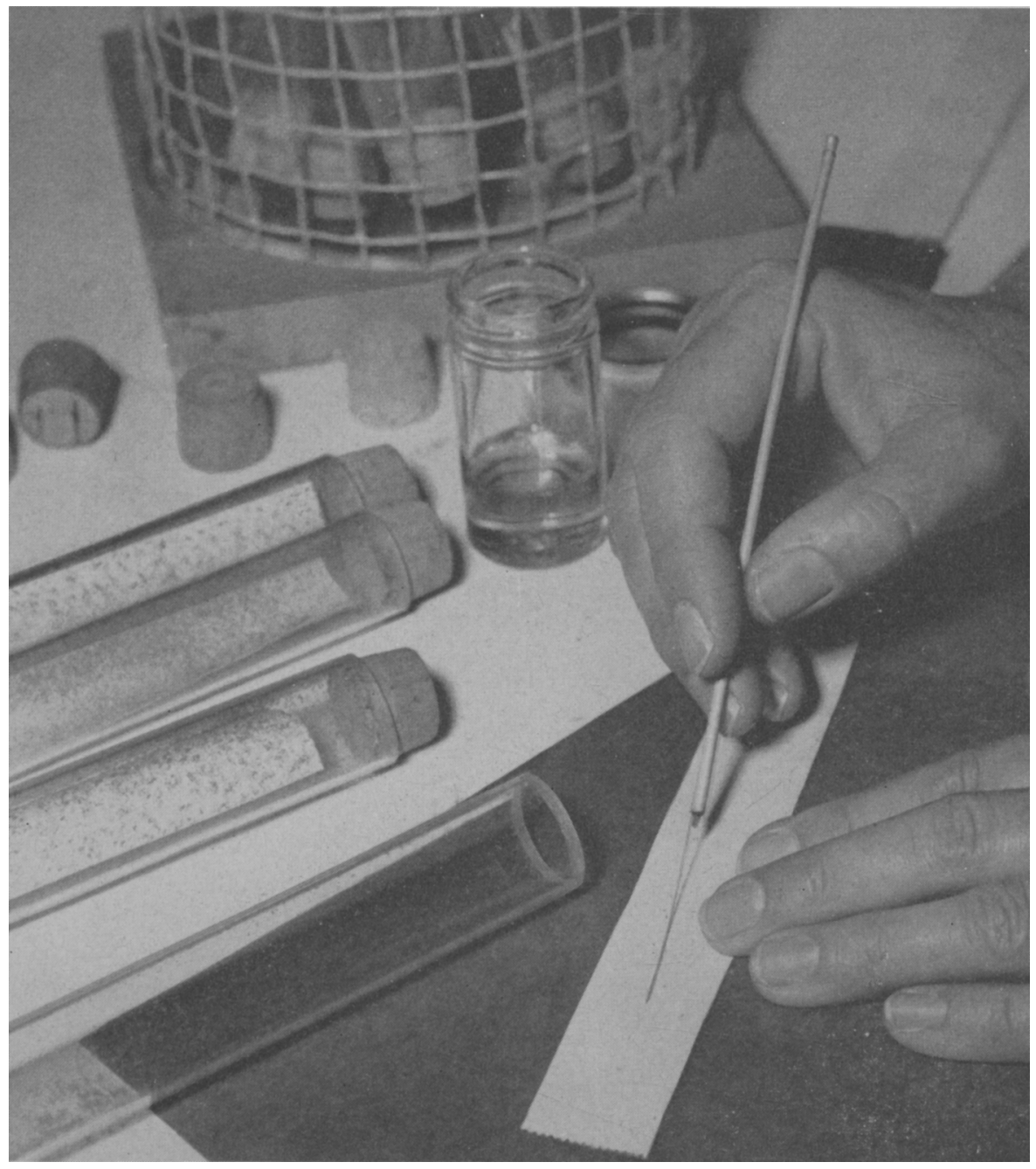

Fig. 17. Preparation of honey papers with lines of undiluted honey for insertion in collecting tubes.

hopper (see figures 10 and 11). Each tray holder is provided with a pair of hooks to hold one end of the tray. Each hook has a flange on the outer side to catch on the side of the hopper and hold the tray in position with the top of the potatoes $11 / 2$ inches below the top of the hopper.

\section{Parasite-collecting equipment.}

Adult parasites are collected by air suction into transparent plastic tubes, which are 8 inches in length. This length is needed to provide an air cushion to minimize injury to the parasites when they are sucked into the tube. The tubes are 1 inch in outside diameter and have walls 1/16 inch thick. They are closed by inserting a cork in each end (fig. 19). The corks used are size No. 9 


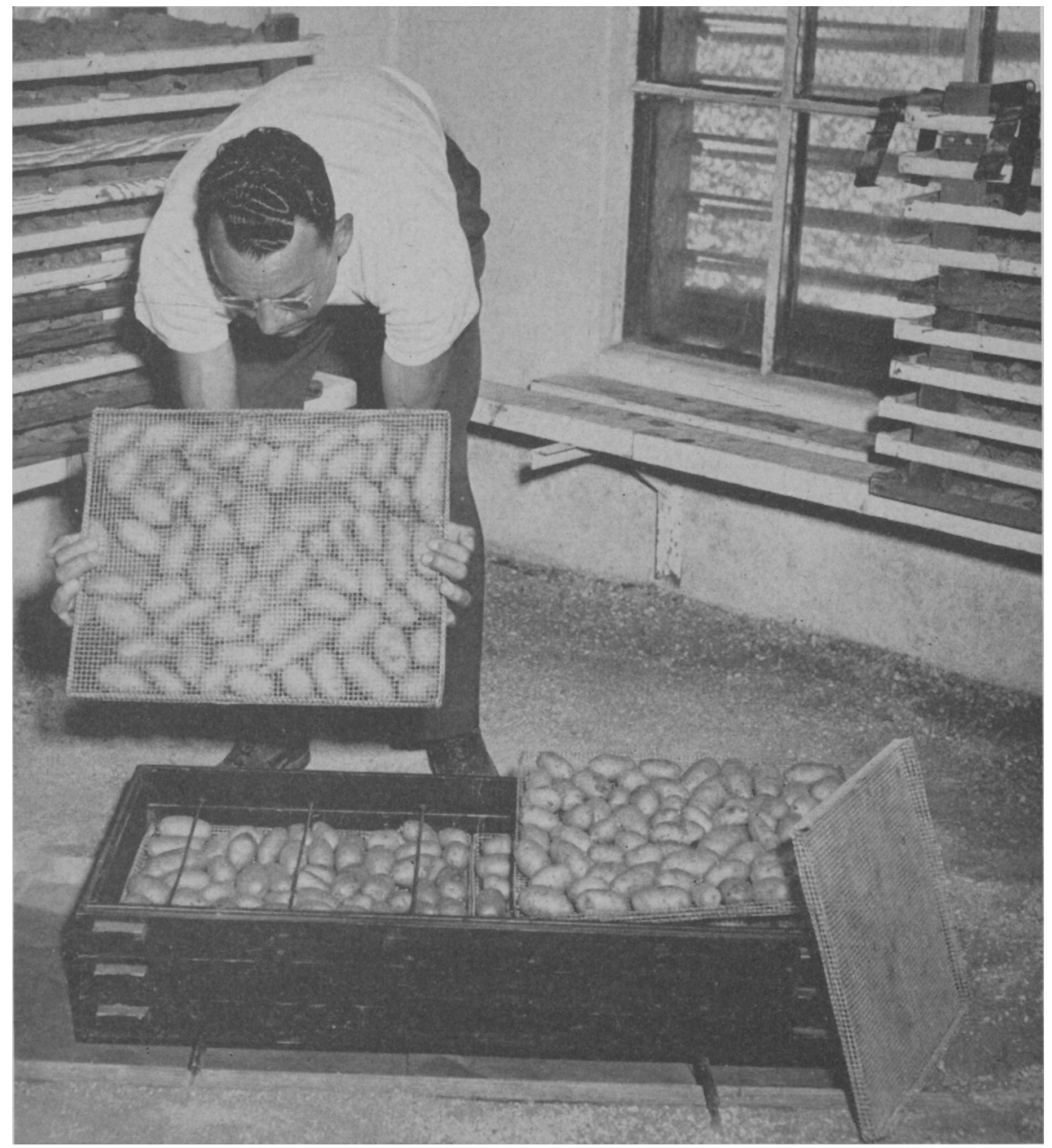

Fig. 18. Turning potatoes 18 hours after infesting upper side. Note hardware cloth flats with sides half the depth of a potato in height and solid side frames with steel rods six inches apart to support the flats.

short and are inserted large end first to eliminate crushing of parasites between wall of tubes and cork. The inner edge of each end is slightly beveled to prevent cutting the corks. The parasites are gathered into the tubes (fig. 20 ) by means of a suction collector. The collector, or aspirator, consists of a rubber stopper through which a collecting nozzle and air outlet filter tube connect with the vacuum line.

The nozzle consists of $3 / 8$-inch brass pipe 3 inches in length. The intake or outer end is flattened to form an opening $1 / 16^{\prime \prime} \times 3 / 8^{\prime \prime}$. At each end of this opening the pipe wall projects $1 / 16$ inch so that when the nozzle is appressed to surfaces bearing the parasites, the opening is held $1 / 16$ inch away from it. The projections should be slender in order to minimize injury to parasites. 


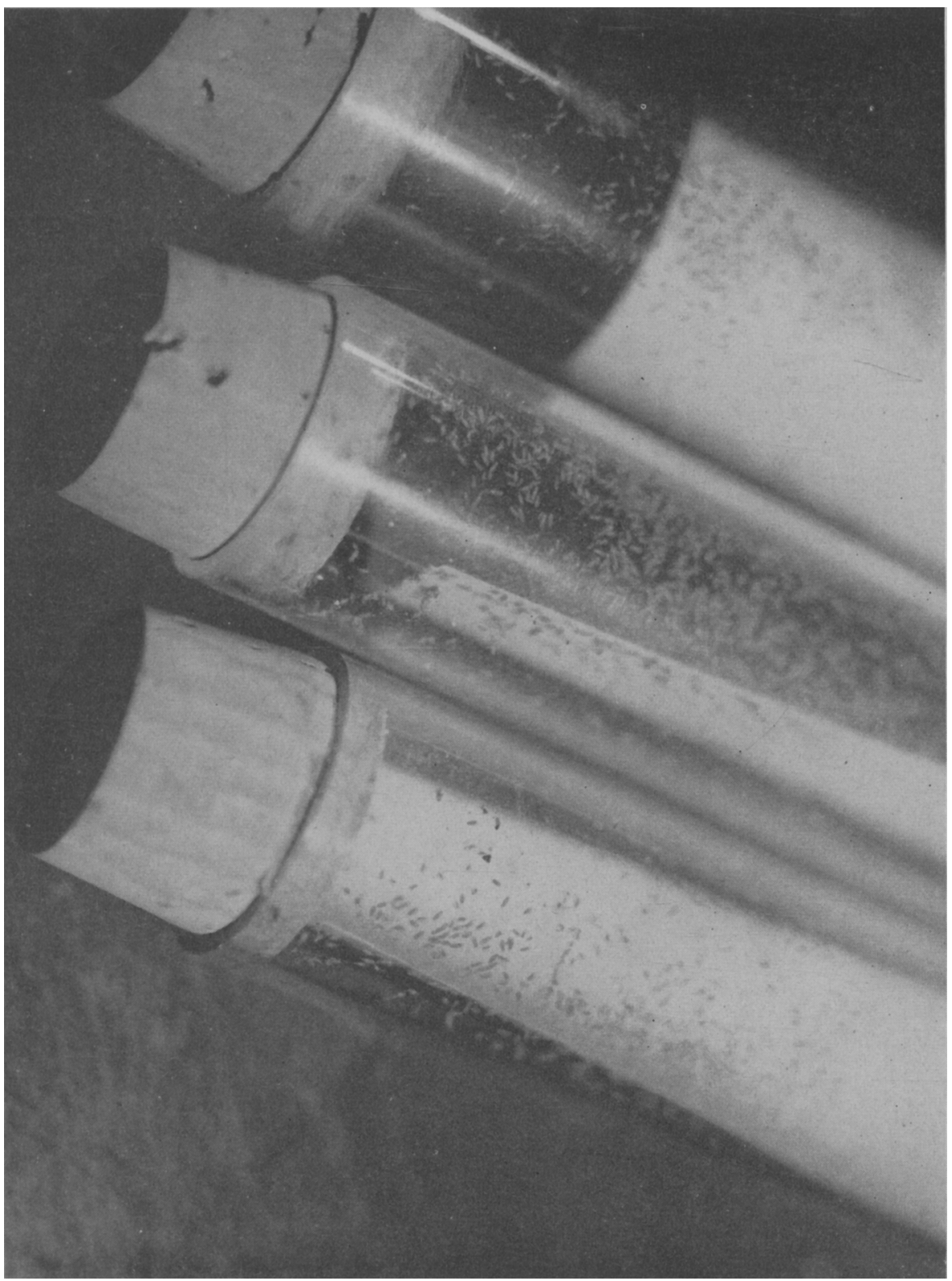

Fig. 19. Ends of parasite-filled collecting tubes showing honey papers and inverse method of placing the corks to prevent destruction of parasites. 


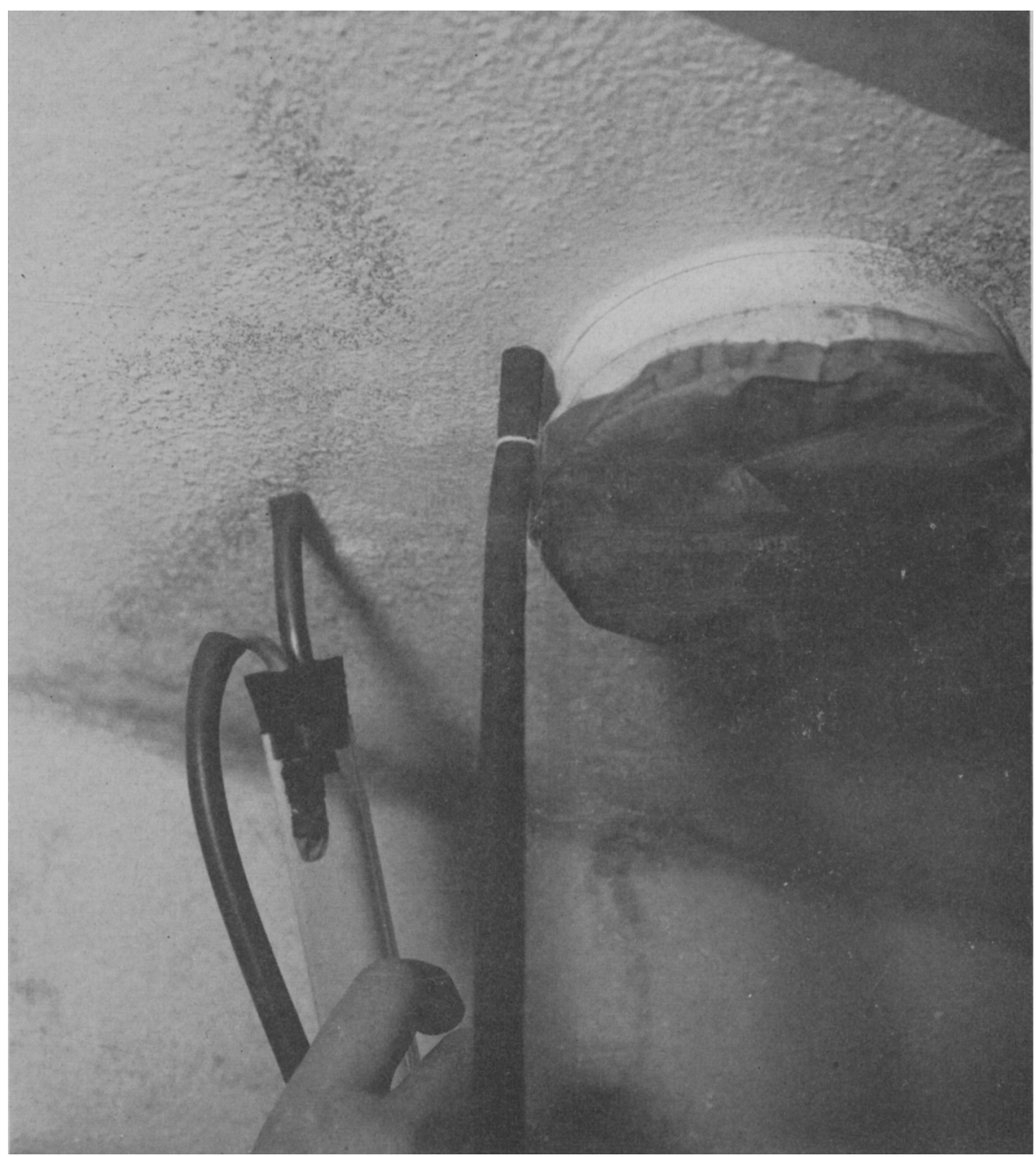

Fig. 20. Ceiling of emergence room showing Aphytis sp. "A" adults congregated over a period of four hours in air blast from air hose in center with its opening appressed to ceiling. The collecting operator is in position for collecting the massed parasites.

Amount of Equipment Needed for Commercial Production. The production capacity of an insectary is measured by the number of female parasites produced per unit of time. On the basis of experimental production in 1950, in which an average of 500,000 Aphytis females per month were produced for release during a 3-month period, it is estimated that the production of at least 100,000 females of $A$. chrysomphali per day would require the use of 250 pounds of grapefruit (10 trays) per day; to obtain 100,000 females of Aphytis sp. "A" per day would require 200 pounds of egg-sized potatoes (10 trays) per day. These amounts include the material needed for mother infestations, which come to about 1 tray per day. 
The amount of equipment needed to handle such production is as follows : Infesting frames and flats to:

Hold potatoes one day while infesting and one day for establishment of crawlers-20 frames and 40 flats.

Reinforced wire trays to: No. trays

Warm potatoes prior to fumigation $\ldots \ldots \ldots \ldots \ldots \ldots \ldots, 10$

Hold fumigated potatoes during aeration ............ 20

Hold material for parasite production $\ldots \ldots \ldots \ldots \ldots \ldots \ldots 180$

Hold developing mother stock . . . . . . . . . . . . . . 30

Hold producing mother stock . . . . . . . . . . . . . . 40

Hold reserve mother stock ..................... 40

Hold material during parasitization and parasite development 108

Hold material during parasite emergence . . . . . . . .... 90

Hold in reserve $\ldots \ldots \ldots \ldots \ldots \ldots \ldots \ldots \ldots \ldots . \ldots \ldots$

548

The amount of other equipment needed is readily figured out on the basis of number of trays to be used and number of parasites to be produced.

\section{PRODUCTION PROCEDURES}

With Aphytis spp. the continuity of production essential to efficient use of labor and material necessitates the segregation of the basic operations : 1) the preparation of the host-supporting medium ; 2) the propagation of the host; and 3) the culture of the parasite. These operations are conducted at the highest rate feasible to minimizing the amount of space and equipment needed to produce a given number of parasites, the number of parasites produced per unit of space and time being the criterion of operation efficiency.

Preparation of the Host-supporting Medium. The egg-sized White Rose potato tuber of the smooth-skinned, flat type (ideal size $2^{\prime \prime} \times 3^{\prime \prime} \times 11 / 2^{\prime \prime}$ ) is the most suitable medium for the production of certain species of scale insects, such as red scale and ivy scale (Aspidiotus hederae). Since such scales are sessile, surface-infesting organisms generally dispersed by air currents when in the mobile crawler stage, the potatoes in preparation for infesting are placed so that the maximum amount of surface is exposed. This is done by placing the potatoes in trays one layer deep. Prior to setting up each tray, 2 infesting flats are placed in it for use later in removing the potatoes to the infesting frames. Since the White Rose potatoes are usually obtained from areas inhabited by the potato tuber moth, Gnorimoschema operculella (Zell.), and the potato mealybug, Pseudococcus solani Ferris, the potatoes after being trayed are fumigated at $80^{\circ} \mathrm{F}$ for 2 hours with methyl bromide (55 cc per $100 \mathrm{cu}$. ft.) (figures 7 and 8). In cold weather the potatoes should be thoroughly warmed prior to fumigating. Subsequently the treated potatoes are held at $80^{\circ} \mathrm{F}$ for 2 days before infesting to insure freedom from gaseous methyl bromide which is lethal to young scale. On the afternoon of the third day after fumigation, the trayed potatoes are moved to the infesting room, and the infesting flats of potatoes removed to the infesting frames. 
Propagation of the Host. It is advisable to have a backlog of mother infestations for emergency use. To provide for this, mother infestations are placed in storage at temperatures between $55^{\circ}$ and $60^{\circ} \mathrm{F}$. If a tray of potatoes infested with scale due to reproduce in 2 or 3 days is placed in storage each day, and after 30 days removed to the infesting room, an emergency stock of 30 trays of mother scale is always on hand for use, should the infesting stock become contaminated with pests, such as mealybug or tuber moth.

Scale infestations for use as mother stock are moved from the storage room to the infesting room as needed. The infested potatoes remain there as long as the infestations produce crawlers in adequate numbers, which may be over a period of 3 or 4 months. During this period, one half or more of the potatoes may deteriorate from rot. These are discarded at regular intervals, and the tray contents combined so that all trays are kept filled. The potatoes that produce scale for 4 months or longer gradually shrink in size and become brittle.

In the daytime the young scales emerge and move to the upper portions of the potatoes. They are transferred to fresh potatoes twice a day. In the removal of the crawlers from the mother infestations to the potatoes in the infesting frames, 3 frames of potatoes are stacked one upon the other on 2 crossbars set 2 inches above the floor (the use of only 3 frames at a time is merely a matter of convenience). The transfer hopper is then lifted and fitted to the top frame of the stack (see fig. 9). With the hopper in position, a tray of mother stock is lifted by a pair of metal tray holders and set into the top of the hopper (see fig. 10). The crawlers on the mother infestation are then transferred to the fresh potatoes. An air blast from the compressed air brush which is passed 6 times along the top of the hopper $11 / 2$ inches above the potatoes in the tray is regulated so that its pressure is sufficient only to remove the crawlers (about 25 pounds of pressure with 35 openings in air brush).

The air-borne crawlers drift through the air space below onto the potatoes, onto the walls of the hopper, or through the 3 layers of potatoes onto a sheet of paper beneath. Since a greater number of crawlers tend to fall on the potatoes at the edges of the frames, the flats after the infestation is half completed are reversed, bringing the potatoes at the middle of the frame to the edge of it. The numbers of erawlers adhering to the walls of the hopper and caught by the paper beneath are sufficient to infest 2 additional trays.

The complete infesting of 10 trays of potatoes requires the crawlers produced each day by about 40 trays of high-producing mother stock.

Each tray is blown twice every 24 hours, beginning in the forenoon about 10 o'clock and in the afternoon about 3 o'clock.

The handling of the 3 potato-filled frames beneath the hopper in order to effect the transfer to the potatoes of all of the scale blown from the mother stock of 40 trays is as follows: When first set up, the potatoes in the 3 frames receive the crawlers from 10 mother trays, the flats of the top frame being reversed after 5 mother trays are blown. Then the top frame is placed at the bottom of the stack and the potatoes then receive crawlers from 7 mother trays, the flats of the top frame being reversed after 3 mother trays are blown. Finally, the second top frame is placed at the bottom, the flats in the third 
top frame are reversed to begin with and the stack blown with 2 mother trays. All 3 trays are then equally infested.

At each forenoon and afternoon blowing, the crawlers that have accumulated on the side of the hopper and on the paper beneath the stack of frames are used to infest 2 additional frames of potatoes. The air brush is used to remove them from inside the hopper adhering to the walls and from the paper after it is removed from under the stack and held suspended in the hopper.

On each afternoon the potatoes that were infested during the forenoon are then turned upside down. To accomplish this, each flat of potatoes is removed from the frame, covered with an empty flat and the 2 flats, held tightly together, turned upside down (see fig. 18). The flat of potatoes is then replaced in the frame for the completion of infestation.

Each egg-sized potato when completely infested should carry about 1,000 female scales, evenly distributed over its surface. The ability of the operator to obtain such an infestation comes with practice. Potatoes that are to be used for mother stock should be very heavily infested. Those to be used for Aphytis production should be so infested that later, when the females are in the late gray stage, there is little if any overlapping of the scale covers.

After being completely infested, the potatoes are held for an additional day in the frames. They are then transferred back to trays by removing the flats to a thin wooden plate about the length and width of a tray, inverting an empty tray over them and, holding the plate and tray firmly together, turning the whole assembly so that the potatoes will then occupy the tray.

The trays of newly infested potatoes are then placed on racks in the holding rooms, where those that are to be used for parasite production are held until suitable for parasitization. An infestation is ready for parasitization when in most of the scales the scale body is free of the second molt skin. When 10 trays are infested daily, 9 are used for parasite production and 1 for mother stock.

Propagation of the Parasite. In the procedure of propagating Aphytis spp., efficiency in parasitization involves the introduction of host populations into a parasite population (Flanders, 1949). In building up stocks of the parasites it is necessary at first to use small units, such as the sleeve cage (fig. 21). When this cage was used for the production of the Chinese golden chalcid, 20 well-infested potatoes exposed to attack by 1,000 or more females for 4 days yielded about 5,000 progeny. The parasite population in the sleeve cage was maintained by replacing in the cage at more or less regular intervals infested potatoes from which adult parasites had begun to emerge. A constant parasite production, however, cannot be expected by using this method of inoculation unless the scale population, as well as the emerging parasite population, in such replacements is quite constant. The red scale infestations used for Aphytis culture are made up of individuals of equal age which, at high humidities, are approximately equal in rate of development. Since the susceptibility of such infestations to parasitization is limited to a shortperiod-of-life cycle the scale during such periods must be exposed to a parasite population sufficient to obtain a high percentage of parasitization with a minimum amount of mutilation.

In the commercial production of the golden chalcids, their emergence must 
not occur in the parasitization room since, for efficient operation, it is essential that the ratio of the parasite population to the exposed host population remain constant.

The number of parasites released daily in the parasitization room corresponds to the amount of mating-stage red scale placed therein each day. The parasites remain in the room and form a population constant in number. It is estimated that in the insectary the average life of the adult Chinese golden chalcid is about 10 days.

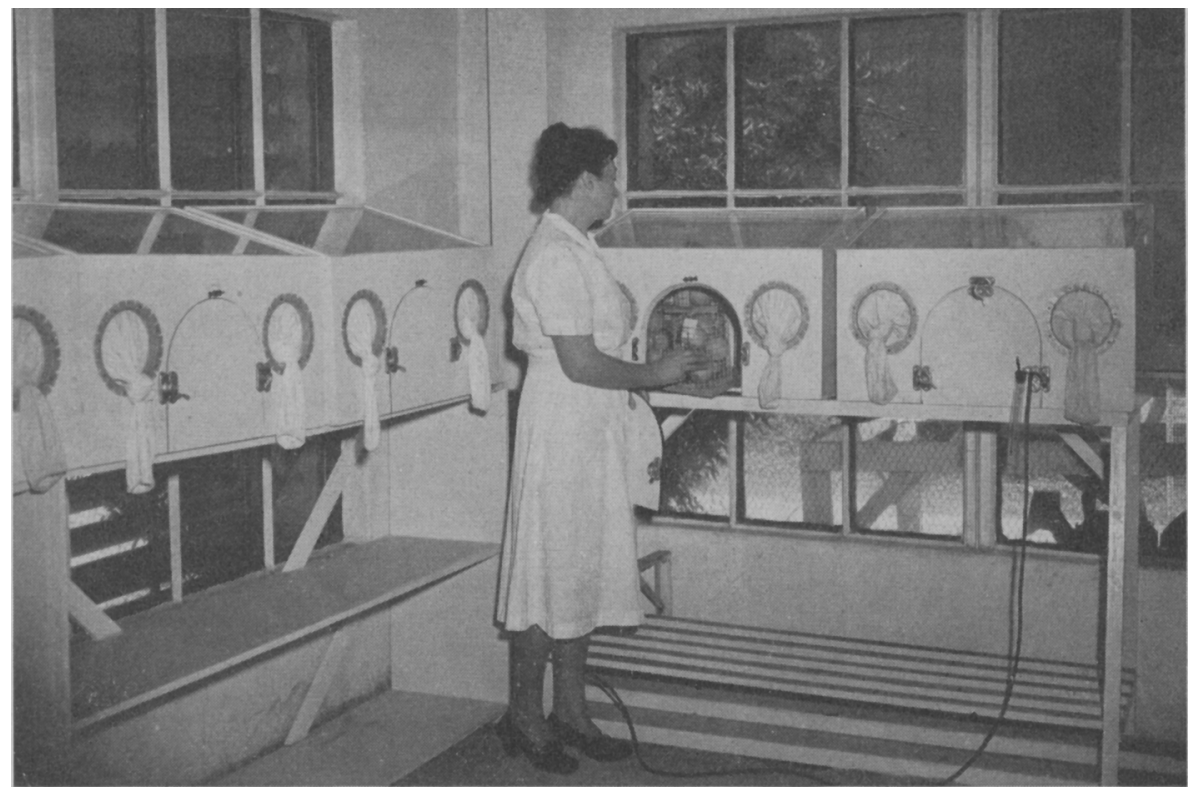

Fig. 21. Sleeve cages for initial production of parasite and for holding reserve stocks.

In the production of the California golden chalcid on red scale infested lemons, 5,000 females were used per tray per day with the lemons infested only on one side. With grapefruit infested only on one side, the daily inoculum should not exceed 2,000. The maximum daily production from 2 trays of infested lemons was 35,000 females. The average tray of properly infested potato tubers will have more than 100,000 third-stage scales suitable for parasitization. The accumulated inocula needed to adequately sting such a tray should not exceed 20,000 females.

The daily inoculum consists of newly emerged females from the emergence room. This may be blown from the tubes onto the newly introduced infestation (see fig. 14), or the tubes may be placed on the tray-the ends open and toward the window. The trays bearing the fresh host infestations are exposed to parasitization in the parasitization room in front of and close to the window and near the ceiling, since the parasites are positively phototropic and negatively geotropic. The tray is set at an angle of $\mathbf{4 5}$ degrees to the horizontal facing the window (see fig. 14). It remains in this position 24 hours and is 
then removed and placed in reverse position on the runners below. After 24 hours in this second position it is set back and away from the window. The parasites remaining on the tray subsequently fly back to the lighted part of the room. One day prior to the commencement of parasite emergence from the stung tray, it is taken to the parasite emergence room.

The parasites in the parasitization room are supplied with honey placed in hairline streaks on the window. The air in the room is maintained at a relative humidity between 50 and 60 per cent to keep the honey from becoming either sticky or moldy. The parasites fly to and fro between the window and the tray. With favorable oviposition conditions, each female parasite may deposit about a half-dozen eggs per day. Oviposition therefore makes up only a small portion of the daylight activity, most of which is concerned with host feeding, host probing, and locomotion.

The parasitized infestations remain in the emergence room during a period of about 10 days, at the end of which time practically all the parasites have emerged as adults. As with the mass production of other entomophagous insects, complete kill of the host population rarely, if ever, occurs. This may be a spoor effect. With red scale and Aphytis, parasitization does not occur in the emergence room since most of the red scale by then has developed beyond the host stage, and the infested potatoes are removed before the next generation of scale attains the stage suitable for parasite development.

All of each day's emergence of parasites should be removed from the emergence room since they have a tendency after 24 hours to return to the red scale infestation and to search for suitable hosts. In this process of searching, the full-fed larval and pupal stages of the parasites are subjected to mutilation action by the adult females. To preclude any mutilation, the parasites should be collected as often as economically feasible.

Parasites are collected by means of an aspirator inserted in a plastic tube (see fig. 20). The nozzle of the aspirator is appressed to the surface bearing the parasites and moved rapidly back and forth, the $1 / 16$-inch points allowing the nozzle to pass above the parasites which are then caught in the air stream and carried into the tube. The velocity of the air stream must be so adjusted that the parasites are drawn into the tube without injury. The collecting surfaces in the emergence room should be hairlined with honey as needed.

Production figures are based on the number of parasites collected per tube; consequently, the number per tube should be constant. Since the numbers are to be estimated, a constant number insures maximum accuracy. In 1950 the number to be collected per tube was set at 1,000.

Hand-collecting with an aspirator has two distinct advantages. The parasites have a chance to feed before they are collected, and a predetermined number can be collected per tube. Automatic collection is advantageous only when the parasites are to be released en masse with their distribution to the pest-infested plant dependent on subsequent flight. The proper feeding of the golden chalcid under conditions of automatic collection is difficult.

When parasites are to be held in the collecting tubes for longer than a half day at normal temperature they should be provided with honey. This is accomplished by placing in the tubes, after the collection of parasites, strips of paper bearing hairlines of honey (see fig. 17). In preparing the tube for the 
honeyed strips, it is held vertically and sharply jarred to force the parasites into the lower end of the tube. This permits opening the upper end and inserting the honey strip.

Collection of the Chinese golden chalcid is facilitated by passing a steady air blast over the illuminated collection surface of the emergence room. Parasites that move into the air-blast area head toward this source of air and move forward until stopped by the air pressure against them. There they remain as long as they are able to retain a foothold on the surface (see fig. 20). The parasites are thus forced to congregate in large numbers and require less labor in their collection.

Release of Parasites. In making releases the collecting tubes are taken to the field, and at the point of release the parasites are ejected either by blowing sharply into the tubes or by striking one end with a short piece of rubber garden hose.

\section{PEST ORGANISMS AND SANITATION}

It is essential to maintain mother infestations and their supporting medium (potatoes or grapefruit) free of pest organisms which may be either competitive or predatory. The material used for parasite production should be utilized so rapidly that it will be impossible for the pest to build up to damaging proportions.

Potatoes need to be fumigated with methyl bromide to eliminate tuber moth and mealybugs. The treatment of grapefruit is necessary to prevent infestations of mealybug and red spider and to eliminate any parasites and predators of red scale that may be brought from the field.

Routine measures to prevent the interruption of production by pests are the temporary cold storage of mother stock and its rapid turnover when in use, the destruction of used material, the separation of breeding stocks by pest-proof barriers, the destruction of possible sources of pests in the neighborhood of the laboratory, and routine sterilization of all equipment and material.

The use of host material equal in age tends to prevent the build-up of pests that attack only certain stages, provided that the interval between the suitable stages tends to starve out the pest.

The sugar mite (Tyroglyphus sp.) may cause injury to golden chalcid developing in scale on grapefruit. In order to maintain grapefruit in a turgid condition, it is necessary to hold them at humidities in excess of 70 per cent, which favors the build-up of the mite. Incipient infestations may occur under the buttons on the fruit. Waxing of the stem end, however, eliminates this hazard. The mite Hemisarcoptes malus Shimer may cause damage when red scale with overlapping generations is used.

Scales such as the latania scale, Hemiberlesia lataniae, if not suitable for Aphytis culture may become pests if present in the mother stocks of red scale. The latania scale on the potato is superior to red scale in reproductiveness. It can be readily eliminated, however, by screening it out through the propagation of the mother stocks on grapefruit for one generation. Using grapefruit as a temporary medium for mother infestations will also eliminate tuber moth. 
The Chinese golden chalcid reproduces readily on the ivy scale, Aspidiotus hederae (Vallot), but this scale has not been used to any great extent because of its white scale cover which obscures incipient infestations of mealybugs, and its susceptibility to attack by Hemisarcoptes malus. The conditions under which it is necessary to hold the mother infestations are ideal for the build-up of these pests.

A basic principle in the culture of organisms is the ascertaining at frequent intervals of their condition and state of development. Fluctuation in production can thus be anticipated and the factors detrimental to maximum production eliminated before serious losses occur.

During the month of June, 1950, the Division of Biological Control Insectary at Riverside produced for release alone about one million Chinese golden chalcids. About 300,000 of these could not be released, however, because they were trapped and killed in the air inlet of the emergence room. These trapped individuals had entered a narrow crevice between the air inlet screen and the air duct, in their positive anemotropic response to an air stream from this crevice.

Economic Consideration. The profitableness of periodic releases of the golden chalcids depends on their searching capacity when released in large numbers and the use of methods for economically producing and releasing such numbers (Smith, 1946; DeBach, Dietrick, Fleschner, and Fisher, 1950).

Release procedures are of two general types, accretive and inundative (Flanders, 1930). Control of a pest through the use of accretive releases depends on the action of subsequent generations of parasite progeny. Continuity of the host stages of the pest in time and space is essential. It appears to be the only type of release that could be economically used against pests of such crops as sugar cane, that are characterized by relatively large hostinfested surfaces per acre.

Control of a pest through the use of inundative releases depends largely, if not entirely, on the parasite populations released, not on their progeny. Its economic use appears limited to the control of pests infesting crops of high value having relatively low host-infested surfaces per acre. It is the only method to use in controlling pests having host stages discontinuous in time and space. Such releases should be made at intervals timed so that, in the area that they can search, the parasites are present in numbers greatly exceeding those of the host population. To do this economically means producing the parasites cheaply and making the releases when the host population is low.

The release of parasites in inundative amounts is a type of control analogous to spraying and dusting in that a greater amount of lethal material is used than is actually effective, that repetition may be necessary, and that the effect is more or less immediate (Flanders, 1930a). In the control of red scale by releases of the golden chalcid, it is highly probable that only the use of the inundative method will be economically feasible.

By using the culture methods and equipment described in this paper the total cost (interest on investment, depreciation, et cetera) of one day's production of the golden chalcids should be less than $\$ 50$. If the work is handled efficiently, the number of parasites produced per day should be between 
100,000 and 500,000. This production requires the services of 2 well-trained men working full time 7 days a week, given adequate equipment and housing facilities, and using each day 200 pounds of potatoes properly infested with red scale. In estimating costs of production, an allowance should be made for 10 per cent culls in each 100 pounds of commercially packed seed potatoes.

The efficient production of golden chalcids depends ultimately on the efficiency of the insectary operators. As with the culture of most organisms, constant attention to detail is required.

\section{ACKNOWLEDGMENTS}

The writer is greatly indebted to Louis Dawson, Senior Laboratory Technician, and Vera Richards, Laboratory Technician, for valuable assistance in the development of golden chalcid culture methods. 


\section{LITERATURE CITED}

BartlettT, Blair R., and T. W. Fisher.

1950. Laboratory propagation of Aphytis chrysomphali (Mercet) for release against California red scale. Jour. Econ. Ent. 43:802-06.

DeBach, Paul, C. A. Fleschner, and E. J. Dietrick.

1948. Natural control of the red scale on eitrus. California Citrog. $34: 6,38$.

DeBach, Paul, E. J. Dietrick, C. A. Fleschner, and T. W. Fisher.

1950. Periodic colonization of Aphytis for control of the California red scale. Preliminary tests, 1949. Jour. Econ. Ent. 43:783-802.

Finnex, Glenn L., Stanley E. Flanders, and Harry S. Smith.

1947. Mass culture of Macrocentrus ancylivorus and its host, the potato tuber moth. Hilgardia $17: 437-83$.

Flanders, Stanley E.

1930a. Mass production of egg parasites of the genus Trichogramma. Hilgardia 4:465501.

1930b. Evaluation of Trichogramma liberations. Jour. Econ. Ent. 23:886-87.

1942. Metaphycus helvolus an encyrtid parasite of the black scale. Jour. Econ. Ent. 35:690-98.

1943. Mass production of the California red scale and its parasite Comperiella bifasciata. Jour. Econ. Ent. 36:233-35.

1944. Observations on Comperiella bifasciata an endoparasite of diaspine coccids. Ent. Soc. Amer. Ann. 37:365-71.

1947. Use of potato tuber in mass culture of diaspine scale insects. Jour. Econ. Ent. $40: 746$.

1948. Biological control of yellow seale. California Citrog. 34:56, 76-77.

1949. Culture of entomophagous insects. Canada Ent. 81:257-74.

QUAYLE, H. J.

1938. Insects of citrus and other subtropical fruits. 583 pp. Comstock Pub. Co., N.Y.

SALT, G.

1937. The sense used by Trichogramma to distinguish between parasitized and unparasitized hosts. Roy. Soc. London Proc., Ser. B. 122:57-75.

SMITH, HARRY S.

1922. Biological control of insect pests of citrus. California Citrog. 8:47, 53 .

1946. The biological control program in relation to California agriculture. California Citrog. 31:414, 452 .

Smith, Harry S., and Stanley E. Flanders.

1949. Recent introductions of entomophagous insects into California. Jour. Econ. Ent. $42: 995$

Woglum, R. S., J. R. LaFollette, W. S. Landon, and H. C. Lewis.

1947. The effect of field-applied insecticides on beneficial insects of citrus in California. Jour. Econ. Ent. 40:818-20. 
The journal Hilgardia is published at irregular intervals, in volumes of about 600 pages. The number of issues per volume varies.

Subscriptions are not sold. The periodical is sent as published only to libraries, or to institutions in foreign countries having publications to offer in exchange.

You may obtain a single copy of any issue free, as long as the supply lasts; please request by volume and issue number from:

Publications Office

College of Agriculture

Berkeley 4, California

The limit to nonresidents of California is 10 separate issues on a single order. A list of the issues still available will be sent on request. 